\title{
Alcabalas y Diezmos. Economía y estructura del poblamiento en la vega de Granada a través de las fuentes fiscales castellanas (I50I-I506)
}

Pedro Hernández Benito

\section{INTRODUCCIÓN}

Hasta la fecha son poco frecuentes los estudios dedicados a la fiscalidad castellana en el reino de Granada. Se ha estudiado con bastante éxito la fiscalidad mudéjar en algunas regiones, baste citar los últimos trabajos de Antonio Malpica Cuello y Carmen Trillo San José.' Pero no se ha tratado en detalle la aplicación del régimen fiscal castellano en el reino, excepción hecha de las franquicias reales (LÓPEZ DE COCA, J. E., 1979, ps. 205-223, SUBERBIOLA, J., 1.974-75, ps.149-196). Sólo hemos podido consultar las escasas menciones a las alcabalas y diezmos de Granada que figuran en los trabajos de Miguel Angel Ladero Quesada sobre la Hacienda Real Castellana, ${ }^{2}$ el imprescindible trabajo de Manuel Garzón Pareja sobre la rentas de la Iglesia granadina (GARZÓN PAREJA, M., 1974) y algunos estudios acerca de zonas concretas como las Alpujarras (LOPEZ DÍAZ, I. 1992, ps. 39 - 63). Recurriendo precisamente a fuentes fiscales inéditas pretendemos con este trabajo profundizar en el conocimiento de la economía y la organización del poblamiento en la Vega de Granada y su relación con territorios vecinos. La Vega ha sido tratada en numerosos trabajos pero casi siempre concertando informaciones dispersas o realizando análisis parciales como el de Juan
Andrés Luna Díaz sobre la agricultura (LUNA, J.A., 1979, ps. 231-248), o los dedicados a los hábices $\circ$ la toponimia. ${ }^{3}$ El análisis de relaciones fiscales, aplicadas en todo el territorio, nos va a ofrecer una visión global de la región completada y confirmada por otros testimonios ya conocidos.

\section{LAS FUENTES}

Casi todas las fuentes fiscales tratadas provienen del Archivo General de Simancas, son documentos sobre rentas reales y eclesiásticas del reino de Granada desde fines del s. XV hasta mediados del XVI. Ninguno está foliado, así que los citaremos por sus títulos y el legajo en que aparecen.

Hemos estudiado básicamente tres relaciones de alcabalas de las alquerías de Granada de los años 150I, I502 y 1503, y una declaración sobre los diezmos del arzobispado de Granada de 1506. En los mismos legajos donde están éstos hay más documentación que nos ha permitido aclarar algunos detalles. Expondremos en un cuadro los documentos principales y la fecha de redacción entre paréntesis.

\footnotetext{
I MALPICA, A. y TRILLO, M. C., 1992, ps. 247-260, TRILLO, M. C., 1992, ps. 853-878. En éste también figura el diezmo cristiano.

2 LADERO, M.A, 1973. Cft también "La Hacienda castellana de los Reyes Católicos" (1967) Moneda y Credito I03, ps. 81 - 88.

3 Cft los trabajos de Espinar Moreno sobre los hábices y la bibliografía de la nota 39 para la toponimia.
} 


\section{Expedientes de Hacienda}

Legajo 12

- Alcabalas de los cristianos nuevos de Guadix y su partido de 1502 (Madrid, 2-I-I503).

-Relación de la renta de las alcabalas de los cristianos viejos de la ciudad de Guadix de I.50। (Madrid 2-I-1503)

-Relación de la renta de las alcabalas de los cristianos viejos de la ciudad de Guadix de I502 (Madrid, 2- I- I503)

-Renta de los diezmos de Guadix y su partido de 1502 de cristianos viejos y nuevos. (Madrid, $2-1-1503)$

-Arrendamiento de las rentas que entran en el partido de diezmos y alquerías de Granada de 1.495 (28-3-1496)

- Rentas de la alcabala de las alquerías de Granada de I50। (27-5-|502)

- Alcabalas de las alquerías de Granada de I502 (2-I I-I502)

\section{Legajo 18}

-Rentas de las alcabalas de las alquerías de la ciudad de Granada del año de 1503 (redactado en 1504)

\section{Contaduría Mayor de Cuentas, $I^{a}$ Epoca}

\section{Legajo 25}

- Tercias de pan y maravedís de las alquerías de Granada del año de 1510 (redactado en 17-81510)

\section{Legajo 417}

- Declaración sobre los diezmos del arzobispado de Granada del año 1506 (Valladolid 28-81506)

\section{LAS RENTAS DE LAS ALCABALAS $Y$ LOS DIEZMOS EN GRANADA $Y$ SU COMARCA}

Como dijimos antes hemos trabajado principalmente sobre las relaciones de alcabalas y diezmos de la Vega. Ambos tipos de impuestos ofrecen una información inapreciable acerca de la riqueza de los núcleos de población ya que eso es precisamente lo que gravan, el tráfico de mercancías y la producción rural. Analizaremos cada una de las rentas por separado.

\section{I LAS ALCABALAS}

La alcabala es un impuesto que gravaba el comercio interior con un tipo fijo, generalmente era el diez por ciento. Hasta ahora desconocemos el porcentaje que se aplicaba a las alquerías de la Vega. La mayoría de las rentas de la ciudad de Granada son alcabalas sobre el consumo de diferentes productos (lino, madera, fruta, vino, paños, etc.). Las alcabalas de las alquerías de la Vega y Sierra de Granada gravan en cambio el comercio local junto con "... las cosas que los vecinos de las dichas alquerías vendieren en la çibdad de Granada de las cosas que la dicha çibdad es franca syn las heredades de las dichas alquerías que no entran en este encabeçamiento ...", es decir, el comercio local más la venta de productos que tenían franqueza de impuestos en Granada capital menos las transacciones de bienes inmuebles de la comarca cuyos impuestos entraban en la renta de la ciudad (TRILLO, C.., en prensa).

La definición expuesta aquí ha de ser aún más matizada pues la recaudación del impuesto modifica su naturaleza. Los dos sistemas usuales a fines de la Edad Media se aplicaron en la Vega de Granada, el arrendamiento del cobro a un intermediario y el encabezamiento o gestión del pago del impuesto por las autoridades de los lugares afectados (LADERO, M.A., 1973, ps. 22 - 32.). El encabezamiento se usó en la mayoría de las alquerías durante I50 I y I503, mientras que el arrendamiento fue el predominante en I502. En I50I y 1503, no obstan-

\footnotetext{
4 A.G.S., C.M.C. I a época I. 25. Relacion del cargo y data que hace Rodrigo de Avila recaudador que fue de las alquerías de las alcabalas de Granada del año de quinientos y quatro años (en adelante Cargo y data de las alcabalas de 1504)
} 
te, el cobro del impuesto en algunos negocios permanentes como mesones o tiendas fue entregado a arrendadores. Estos se hacían cargo de él mediante subasta aparte de las demás alcabalas de la alquería, la cuál sí se encabezaba. Al ser el método más usual el encabezamiento mediante una cantidad global estipulada, la alcabala deja de aplicarse como una exacción sobre el precio de los productos y no grava ya directamente las operaciones comerciales sino, más bien, la riqueza de cada localidad.

Además del problema anterior se nos presenta otro. En las relaciones de alquerías que hemos estudiado adivinamos más que distinguimos diferentes capítulos de aplicación del impuesto. Pero ninguno parece ser un gravamen sobre productos francos de alcabala en la ciudad. Sabemos únicamente que estas franquezas se aplicaron a Granada capital desde 1500 en una variada gama de bienes: pan, panizo, carnes, aves, caza, vino, paja, leña, leche, alcacer, abonos, cobre viejo, oro y plata, lana, paños, determinados artesanos como calceteros, zapateros, labradores de metales, etc., animales de carga, fruta verde y seca, uvas, aceitunas, huevos, hortaliza, semillas, madera, cal, yeso, teja y ladrillo. ${ }^{5}$ La franqueza sobre los productos citados se aplica sólo a aquellos cristianos que estaban avencindados antes de su concesión en la ciudad, el Albayzín y sus arrabales. Las operaciones hechas entre forasteros y cristianos o entre moros y cristianos o solamente entre moros sí pagan impuesto, al igual que todo lo que vendieren los cristianos moradores en las alquerías. ${ }^{6}$
¿Pero entonces por qué conceptos pagan alcabala las alquerías de Granada? Podemos obtener algunos indicios parciales. En primer lugar por sus vecinos. En I50I las alquerías se igualaban con el recaudador por una cantidad según el padrón de vecinos, el pago de la suma se repartía entre ellos.?

En segundo lugar algunos negocios importantes del lugar como la carnicería, tienda, mesón, almadraba (tejar) o taberna también contribuyen. ${ }^{8}$ El cobro de sus derechos se arrendaba aparte y cabe la posibilidad de que fueran negocios concejiles porque existen otras tiendas en algunos lugares que no se mencionan en las relaciones, por ejemplo las que son bienes hábices. ${ }^{9}$ Junto con algunos de estos negocios figura en 1503 el derecho del viento en Alhendín. Aunque sólo lo hemos encontrado una vez en las relaciones parece que las alquerías lo cobraban dentro del total de las alcabalas. Por ejemplo, en I509 el concejo de Atarfe da un poder a su alguacil para que cobre en el pueblo la alcabala del viento y forasteros. ${ }^{10}$ Con el nombre de 'alcabala del viento y otros derechos de forasteros' se cobra en Guadix y, junto a otros negocios, en casi todas las alquerías de su alfoz durante I502." También figura en otros lugares de Andalucía a fines del s. XV como en el señorío de Lepe y Ayamonte, gravando transacciones irregulares o de forasteros (LADERO, M. A., 1989, p. 360). En Ronda fue pagado por mudéjares y vecinos de Arcos y Gibraltar (ACIÉN, M., 1979, p. 310) y se consideraba un derecho separado del de los descaminados (RAMOS IBASETA, J. R., 1988, p. 56). Sin embargo la explicación más

\footnotetext{
5 Archivo Municipal de Granada. Cartularios y Libros de Copiadores, libro 7.092 fols. $185 r^{\circ}$ - $187 r^{\circ}$

6 Archivo Municipal de Granada. Cartularios y Libros de Copiadores, libro 7.092 fols. $187 \vee^{\circ}$

${ }^{7}$ A.G.S. Exp. Hac. leg. 12 Rentas de la alcabala de las alquerías de Granada de I50I (27-5-1502) (en adelante Alcabalas de I50 I). Albolote pagó sin veinte vecinos que juraron no deber nada. En Maracena los vecinos pusieron viñas y se mandó que no pagaran nada por ese año

8 A.G.S. Exp. Hac. I. I2 Alcabalas de I50 I, figuran carnicerías, tiendas y mesones. Alcabalas de las alquerías de Granada de I502 (2-I I1502) (en adelante Alcabalas de 1502) se mencionan también tiendas, carnicerías y mesones. A.G.S. Exp. Hac. I. I8 Rentas de las alcabalas de las alquerías de la ciudad de Granada del año de 1503 (redactado en 1504) (en adelante Alcabalas de I503), además de los anteriores aparecen almadrabas y una taberna.

9 VILLANUEVA RICO, Ma C. (1.96I): Hábices de las mezquitas de la ciudad de Granada y sus alquerías, Madrid, Cft. páginas 232, 238 , $324,332,337,352,362$. Figura en los de Monachil una tienda que no es habiz pero que tampoco aparece en las relaciones de alcabalas. Puede ser que estos negocios no se citen porque se engloben en la suma que paga la alquería.

10 DE LA OBRA SIERRA, J. M. (1986): Catálogo de Protocolos Notariales: Granada 1505 - 1515 Tesis doctoral leída en la Universidad de Granada en marzo de 1986. Existe una edición parcial publicada por la Universidad. Consultamos el trabajo original, doc. 6I2.

II A.G.S. Exp. Hac. Leg. 12 Alcabalas de los cristianos nuevos de Guadix y su partido de 1502 (Madrid, 2-I-I 503).
} 
completa de su naturaleza está, por ahora, en un párrafo de las alcabalas de los cristianos nuevos de Guadix de 1502 que citamos a continuación:

"La renta del alcabala del viento de esta çibdad que entran en ella los tenderos e herreros e herradores e tintoreros e çapateros e cortidores e forasteros que traxieren a vender a la çibdad qualesquier cosas e las vendieren con el alcabala de lo que vendieren qualesquier ginoveses, florentinos, e lombardos e otros mercaderes de la Ytalia e de forastero a forastero de las cosas que compraren e vendieren e contrataren e cueros e seuo e hunto e el ganado byvo ..." 12

En resumidas cuentas la alcabala del viento y forasteros consistía en un derecho sobre las ventas entre forasteros o entre vecinos de un lugar y forasteros. Podría ser que en la Vega el viento abarcara tanto las compraventas hechas en las alquerías en las que intervinieran forasteros como las ventas de las alquerías a la ciudad de productos francos dentro de ésta, ya que los Reyes habían ordenado que no gozaran de la franqueza de Granada las operaciones con forasteros o entre ellos y que se pagara los derechos correspondientes en los lugares de donde eran vecinos los vendedores. ${ }^{13}$

En tercer y último lugar hay dos rentas en las relaciones que se anotan al final y no se incluyen en cada población, la renta de los almayales y la de las ventas. La primera afectaba a los comerciantes o arrieros que compraban productos en la ciudad para venderlos por las alquerías, éstos pagaban alcabala en Granada y vendían cosas de tiendas, fruta, pescado y aceite. ${ }^{14}$ La renta de las ventas, como su propio nombre indica, atañía a los mesones situados en despoblado. ${ }^{15}$

Además de los conceptos por los que se pagaba están los que pagaban. Como hemos visto antes, contribuían todos los habitantes de las alquerías del alfoz granadino, moriscos - cristianos, y la recaudación solía organizarse desde la ciudad. ${ }^{16}$ Era frecuente que los propietarios cristianos viejos pagaran aparte del concejo de la alquería, formado por cristianos nuevos, ${ }^{17}$ lo que indica que la población de éstas era casi totalmente musulmana. Los lugares que entraban en la relación eran todas las alquerías de la Vega. No estaban incluidas nunca ni Granada (con franqueza para los cristianos viejos y pago de alcabalas separado del de las alquerías), ni la Alhambra (con franqueza aparte), ni Santa Fe (exenta de alcabalas). ${ }^{18}$ Tampoco pagaban nada Huete ni Tejutor porque Fernando de Zafra, su propietario, se negó a pagar, confirmándosele esta exención por los Reyes. ${ }^{19}$

\subsection{LOS DIEZMOS}

El diezmo en Granada era, como en el resto de Castilla, un tributo eclesiástico sobre la producción agropecuaria. Parece igualmente que constituía el diez por ciento de los productos obtenidos, al menos así ocurría a fines del XVI (GARZÓN PAREjA, M., 1974, p. 30). Pero la Iglesia no se quedaba con la totalidad de la renta. La Corona disfrutaba de dos novenas partes en los términos de Granada, Loja, Alhama, Santa Fe, Montefrío, Illora, Moclín, Colomera, Iznalloz, Almuñécar, Salobreña y Motril, quedando los siete novenos restantes

\footnotetext{
12 A.G.S. Exp. Hac. Leg. 12 Alcabalas de los cristianos nuevos de Guadix y su partido de 1502.

13 Archivo Municipal de Granada. Cartularios y Libros de Copiadores, libro 7.092 fols. 178 v y $182 r^{\circ}$

14 Alcabalas de 1503

15 Alcabalas de 1502

16 GARCíA VALENZUELA, H. (1988). Docs. 339 y 367 Presentación de Cartas de recudimiento ante el Cabildo.

17 Alcabalas de 1503

18 Archivo Municipal de Granada. Cartularios y Libros de Copiadores, libro 7.092 fol. 179 v y LAPRESA MOLINA, E., 1979, p. 219 Privilegio hecho en 1499 por los Reyes Católicos eximiendo a Santa Fe de la alcabala y otros impuestos.

19 Alcabalas de 1501 y 1503
} 
para el Arzobispado. ${ }^{20}$ Esta participación real en los ingresos eclesiásticos se denomina Tercias reales y aumenta su proporción en otras regiones como la Alpujarra o Málaga gracias a concesiones papales (GARZÓN PAREJA, 1974, p. 94-95, 235-236, LÓPEZ DÍAZ, Ma I., 1987 p. 41 y n. 5).

Contribuyen con el diezmo tanto cristianos nuevos como viejos (GARZÓN PAREJA, 1974, p. 27) y lo pagan por todos los productos agrarios. La relación de 1506 detalla los diferentes productos sólo en los términos de Granada ciudad, Loja y Alhama, pero creemos que estos apartados deben estar muy resumidos. Mucho más precisa, y coincidente en lo esencial con los apartados de 1506, es la renta de los diezmos de Guadix de 1502. Reproduciremos aquí los capítulos en que se divide:

-Diezmos de corderos, queso y lana y toda cosa de leche.

-Diezmos de pollos, miel, cera y enjambres.

-Diezmos de hortaliza y el alcacer que se vende, habas verdes y secas y garbanzos y todas legumbres.

-Diezmos de capullos de seda.

-Diezmos de trigo, cebada, panizo y centeno.

-Diezmos de la renta de los árboles verde y seca y becerros, potros, lechones, muletos y borricos.

-Diezmos de lino, linaza, cáñamo y cañamones. -Diezmos de vino, haba, pasa y aceituna. ${ }^{21}$

Sólo hay un capítulo de la relación de Granada que no figura en la de Guadix: la renta de los alfareros de la ciudad de Granada. Podría ser ésta una exacción sobre la producción alfarera pero resulta extraño porque sólo deberían pagar rentas decimales los productos de labranza y crianza. En las ter- cias de Granada, sus villas y alquerías de I537 están todas las rentas de la ciudad menos ésta, que es sustituida por la renta del aceite. ${ }^{22}$ Lo mismo ocurre en los diezmos de I543 (GARZÓN PAREJA, 1974, p. 120 y ss.). Quizás se refiera la palabra a cántaros aceiteros. En 1537 también podemos observar como el cáñamo va incluido en la renta de lino de Granada, igual que en los diezmos de Guadix.

En la relación de 1506 también son nombradas varias veces las minucias. Garzón las define como el diezmo de todos los frutos excepto de los cereales panificables (GARZÓN PAREJA, 1974, p. 10I). En las tercias de las alquerías de 1510 se paga únicamente en especie el pan y en maravedís la renta de las minucias. Además se prorroga la entrega del dinero de las minucias de Albolote y Pulianas "... a cabsa del notorio daño de los dos partydos que se apedrearon las viñas, oliuares, huertas e partido .... ${ }^{23}$ Este mismo criterio parece regir en las tercias de 1537 donde las minucias de las alquerías, villas y todas las rentas de la ciudad de Granada, excepto la del pan, se abonan en maravedís. ${ }^{24}$ A pesar de todo, el sistema no funciona así en 1506. Hay excepciones frecuentes como el pan de la ciudad de Granada, pagado en especie y también en maravedís; pero las minucias siempre se pagan en dinero. ${ }^{25}$ En I 506 el pago en especie constituyó un $46 \%$ del total de diezmos de pan y maravedís $y$ el hecho en moneda un $54 \%$.

En cuanto al modo de pago la estimación se hace en el lugar de la cosecha al levantarla y a veces se paga en este momento, conduciendo luego el dinero o la parte de la cosecha a Granada capital. ${ }^{26} \mathrm{Si}$ se paga en especie se hace en fanegas de pan terciado (dos par-

20 A.G.S. C.M.C I a época. Legajo 4I7: Declaración sobre los diezmos del arzobispado de Granada del año I506 (Valladolid $28-8$ 1506) (en adelante Diezmos de 1506) Ver el reparto de lo que montó el diezmo entre los diferentes capítulos del arzobispado y los dos novenos o tercias reales. Y Legajo 25. Tercias de pan y maravedís de las alquerías de Granada del año de I5 I0 (redactado en I78-1510) (en adelante Tercias de 1510)

21 A.G.S. Exp. de Hac. Leg. 12. Renta de los diezmos de Guadix y su partido de 1502 de cristianos viejos y nuevos (Madrid, 2-I- I503)

22 A.G.S. C.M.C. I a época, leg. 417. Copia de los maravedís de las tercias de Granada y sus villas y alquerías, año de 1537

23 Tercias de 1510 , plazos de los pagos después de la declaración de lo que valió Santa Fe.

24 A.G.S. C.M.C. I a época, leg. 417. Copia de los maravedís de las tercias de Granada y sus villas y alquerías, 1537.

25 Diezmos de 1506. Cft también Chauchina, Alhama, Montefrío y Colomera.

${ }^{26}$ GARZON PAREJA, M., 1974, p. 92 y ss. Y Diezmos de 1506. Se descuenta del ingreso total del diezmo los gastos del acarreo del pan a Granada. 
tes de trigo y una de cebada), ${ }^{27}$ en algunas ocasiones no se guarda la proporción y se añade panizo al pago. ${ }^{28}$ Se dan uno o varios plazos para pagar los diferentes productos (trigo, cebada, minucias), incluso al año siguiente. ${ }^{29}$

Al menos desde 1510 los diezmos de las alquerías se encabezaban. ${ }^{30}$ La cobranza fue gestionada por la Iglesia que pasaba a la Corona la parte correspondiente a las Tercias Reales (GARZÓN PAREJA, 1974, p. 28-29). Esto provocó numerosos conflictos entre ambas instituciones como, por ejemplo, el que motivó la declaración de 1506. Hacia I5 I0 la reina $D^{a}$ Juana envía a Diego Méndez de Tablada, contino real, para que averigüe el fraude que cometieron contra ella el arzobispo y mesa capitular de la Iglesia de Granada. El motivo fue haber declarado que se vendió el cereal del diezmo a un precio muy inferior al real de mercado con lo que escamotearon a la Reina una cantidad importante de dinero que se le debía por las Tercias. La Iglesia presentó ante los requerimientos de Méndez de Tablada una declaración de los diezmos de Granada, la Vega, Loja, Alhama y las villas del año de I506. En ella se revisó y aumentó el precio de las fanegas de cereal haciendo una media entre los precios declarados por testigos tomados de oficio y otros presentados por parte del prelado, deán y cabildo.'

El total de la renta se distribuía en 1506 de la siguiente manera: dos novenos para la Corona y el resto queda para la Iglesia de Granada. De este resto un II'9 \% va para la Mesa Capitular, otro para las fábricas de las iglesias y otro para los hospitales de Granada, sus villas y alquerías. Finalmente un 31 '। \% se destina al prelado y otro tanto a los beneficiados. ${ }^{32}$

\section{PREPARACIÓN DE LOS DATOS.}

Para el análisis económico y del poblamiento en la Vega de Granada y su relación con regiones próximas aprovechamos básicamente las relaciones de alcabalas y diezmos antes citadas. Las alcabalas facilitan unos datos muy minuciosos sobre los lugares de Granada salvo la capital y Santa Fe. En cambio los diezmos agrupan las alquerías en partidos fiscales más amplios pero figuran además Granada ciudad y Santa Fe, las villas y las regiones de Loja y Alhama. Asimismo las alcabalas nos ofrecen una evolución de la renta en un periodo corto, mientras que el diezmo sólo refleja la situación de 1506. Ambas fuentes tienen una naturaleza fiscal y una fecha diferentes pero las dos nos hablan de la riqueza de los lugares de la Vega a comienzos del XVI. Como veremos más adelante, coinciden en lo fundamental aunque está claro que sólo las rentas decimales nos servirán para comparar la producción rural de la Vega con la de otras regiones del reino. Una vez determinada la utilidad de estos documentos pasamos al trabajo sobre ellos.

Las alcabalas son las que más problemas han planteado. En ellas constan gran número de lugares (sobre unos sesenta), pero con muchos detalles particulares que hemos simplificado. A veces falta la cantidad pagada por algún lugar en uno de los tres años, casi siempre en el intermedio. Otras veces el pago de una alquería figura un año individualizado y otro englobado, junto con otras poblaciones, en una suma única. También hay lugares que son mencionados pero que no pagan nada en ningún año por diversos motivos.

Hemos intentado, con el fin de conseguir una imagen lo más precisa posible de la

\footnotetext{
27La fanega mide en Granada 500 estadales cuadrados o 4.697 '06 ms. cudrados. Cft. VALLVE BERMEJO, J. (I976): “Notas de metrología hispano-árabe. El codo en la España musulmana (I)" Al-Andalus XLI, p. 353.

${ }^{28}$ Diezmos de 1506. Cft. los casos de Albolote, Alhendín, Loja e Iznalloz.

29 Tercias de 1510, plazos de los pagos después de la declaración de lo que valió Santa Fe.

30 Tercias de 1510, cft. el final del documento.

${ }^{3}$ I Diezmos de 1506. Al principio se valora la fanega de trigo en 100 maravedís y la de cebada en 50; en la relación presentada ante las averiguaciones de la Reina la fanega de trigo valió 21 I'5 mrs., la de cebada 95'5 y la de panizo I50.

32Diezmos de 1506. Repartimiento: Al prelado 1.757.044. A los beneficiados 1.757.044. A las tercias de su Alteza I.56I.808'5. A la Mesa Capitular 650.747. A las fábricas 650.747. A los hospitales 650.747.
} 
comarca, separar las alcabalas de cada población. Por esto sumamos a la cotización de algunos núcleos la pagada por negocios radicados en ellos y declarados aparte o aceptamos las estimaciones de lo que pueden pagar aunque no lo hayan hecho. ${ }^{33}$ También reconstruimos en ciertos casos el pago de alguno de los tres años que no figura porque no ha sido arrendado el cobro del lugar. ${ }^{34}$ Para ello establecemos una progresión aritmética, es decir la media entre |50| y | 503.

Creemos que esto es justificable teniendo en cuenta que si el impuesto no se cobró fue porque no hubo nadie que arrendara su cobro y no porque hubiera falta de dinero para pagarlo. Asimismo hemos desglosado siempre que hemos podido aquellas cantidades pagadas por dos o más alquerías que en años anteriores o posteriores figuran individualmente. ${ }^{35}$ Esto ha sido hecho mediante el cálculo de la progresión modificada por el porcentaje que supondría respecto de la cantidad total dada para el grupo de poblaciones. Por ejemplo, en Purchil, Belicena y Ambroz primero se calcularían las medias correspondientes a 1502 con los datos de $150 \mid$ y | 503. Sumando las tres medias no nos daría el número exacto que figura en el documento, por lo cual debemos averiguar el porcentaje que cada media ocupa en la suma de las medias y aplicarlo a la cantidad real declarada en el documento. De tal manera que si las sumas de las medias es de 7.895 mrs. y la real de 8.000 , buscamos qué porcentaje supone cada media en la suma de ellas para aplicar éste a la cantidad real de $8.000 \mathrm{mrs}$.

\section{Medias obtenidas con los datos de I50I y I503}

Purchil... 2.950

Belicena 3.160

Ambroz. 1.785

Suma de las medias 7.895

Cantidad total declarada en el documento . .8 .000$
Purchil 2.950 sobre 7.895 $.37 \%$

$37 \%$ sobre 8.000 2.989

Belicena 3.160 sobre 7.895 . $.40 \%$

$40 \%$ sobre 8.000 3.202

Ambroz 1.785 sobre 7.855 $.23 \%$

$23 \%$ sobre 8.000 1.809

Podemos justificar el cálculo de progresiones y el desglose de cantidades globales de las alcabalas basándonos en que las cantidades pagadas por la totalidad de las alquerías y las que pagan cada una por separado se incrementaron desde I50| a 1503 de forma lineal. Sólo en la Malá y el Temple lo pagado en |50| es superior al pago de 1502, aunque después termina en 1503 con una suma superior a |50|. La bajada de 1502 parece ser debida a que no entró en el pago el mesón de la alquería. ${ }^{36}$ A pesar de todo no hemos podido aislar dieciséis lugares de los sesenta, seis agrupados en parejas y diez en un solo grupo. ${ }^{37}$ Estos últimos deben tener una cotización individual pequeña y suelen ser nombrados como 'cortijos de la tierra de Granada' o 'cortijos de la Vega'. Cada grupo de los dieciséis lugares que no hemos individualizado cuentan como una sola alquería en el gráfico 2, excepto cuando el grupo cotizara menos de 10.000 mrs, en cuyo caso cada lugar del grupo sería contado separadamente ya que ni la suma de todos los lugares sobrepasaría el intervalo de cotización más bajo. ${ }^{38}$

Después de todo el proceso de preparación de los datos elaboramos una matriz con ellos donde incluimos la media aritmética de los tres años en cada lugar. Con la media confeccionamos posteriormente los gráficos ya que nos da un valor general para los tres años.

La relación de diezmos presenta menores inconvenientes para su estudio. En primer

\footnotetext{
33 Por ejemplo, Alhendín en 1503, su tienda, carnicería y almadraba pagan una suma aparte de la alquería. Hay algunos más pero no son muy abundantes.

34 De esta manera figuran en 1502 Víznar, Ugijar, Dúdar, Peligros, Hijar y Cúllar. Ver cuadro I.

35 Ver algunos ejemplos en el cuadro I.

36 Ver el cuadro I y el gráfico I

37 Ver el cuadro I.

38 Ver el gráfico 2 "Alquerías de Granada. Alcabalas".
} 
lugar todos los apartados figuraban sólo en dinero excepto parte de los cereales panificables. Convertimos también éstos en maravedís siguiendo la revisión de los precios que se hizo en el documento de 1506. En segundo lugar es característica en esta renta la división en partidos fiscales. Parece que existían dos tipos de partidos que llamaremos comarcales (regiones de Granada, Loja, Alhama y villas de Granada) y locales. Dentro de cada partido comarcal están los partidos locales de la ciudad y, aparte, de las alquerías principales que engloban seguramente a otras secundarias. Tal como aparece en el documento lo hemos reflejado en los cuadros II y III, pero después en los demás cuadros y cartogramas preferimos añadir a la circunscripción de Granada la villa de Santa Fe porque se sitúa en el mismo centro de la Vega. En tercer lugar, la relación presenta sin detallar las cantidades pagadas por las alquerías, sólo aparece a veces el pan entregado en especie o se diferencia el pan de las minucias. Debido a ello no hemos podido delimitar la importancia de los diferentes productos diezmados excepto en las ciudades de Granada, Loja y Alhama. Las conclusiones extraídas del análisis de estas ciudades sólo son orientativas ya que los apartados están calculados en dinero, lo que hace difícil una estimación objetiva del volumen de producción real hasta que no conozcamos el valor en 1506 de todos los productos gravados con el diezmo.

Nos quedan aún por aclarar algunos aspectos referentes a la elaboración del cartograma I sobre las alcabalas de la Vega. Este muestra la situación sólo aproximada de algunas alquerías cuyos restos arqueológicos todavía no se han encontrado, pero que han sido localizadas por diferentes trabajos. ${ }^{39}$ Aparte de los lugares ya estudiados quedan las alquerías de Cújar, Juzeyla y Boali. Se sabe la localización aproximada de Cújar (JIMENÉZ MATA, Ma C., 1990, p. 246), sólo añadiremos que se situaba exactamente en el ya derruido cortijo de San Jerónimo, camino de Alfacar. ${ }^{40}$ En cuanto a Juzeila y Boali parece que estaban al noroeste del Jau y posiblemente dentro del Soto de Roma. ${ }^{41}$ Al Soto lo hemos hecho coincidir con el término municipal de Fuente Vaqueros, que aproximadamente debe equivaler al antiguo coto real. También se ha representado el cauce actual del río Genil en el cartograma, aunque desde el XVI hasta nuestros días las avenidas a veces hayan modificado notablemente su trayectoria. ${ }^{42}$

Por lo que respecta a los datos estadísticos, a pesar de que en el gráfico de distribución de frecuencias hemos agrupado las alquerías según el valor de la alcabala en tramos de 10.000 maravedís, ${ }^{43}$ luego en el cartograma hemos dividido el grupo que englobaba a más lugares (de 0 a 9.999 mrs.) por la mitad (de 0 a 4.999 y de 5.000 a 9.999 mrs.) para que la distribución e importancia económica de las alquerías se pudiera observar con una mayor precisión. Con el mismo objetivo dividimos el lugar de Armilla en dos poblaciones que pagan juntas porque así aparecen en la relación de 1502. Además de los lugares clasificados por la cantidad que pagan también hemos puesto en el mapa aquellos mencionados por los documentos aunque no paguen nada en ningún año. Finalmente creemos que entre $150 \mid$ y 1503 existen otros lugares poblados además de los nombrados en las alcabalas. Posiblemente no figuren por lo poco que pagan o por estar incluidos en el pago de algún núcleo mayor. Hay bastantes de estos citados en I500 por la Bula de Erección de la Iglesia de Granada (SIMONET, F. J., I.872, p. 137).

39 Cft. SECO DE LUCENA, L., 1974, JIMÉNEZ MATA, Mª C., 1990. Para Darabenaroz y Dialfate cft. HERNÁNDEZ BENITO, P., 199।," ps. $61-64$.

40 LÓPEZ, T., 1990, SEGURA GRAí̃̃o, C. y DE MIGUEL, J. C. (editores). Granada, p. 195, figura como Gújar.

4 I DE LA OBRA SIERRA, J. Mª: Catálogo de Protocolos Notariales... Doc. n 565, escritura de fundación de mayorazgo de 1509.

42 MADOZ, P. (1987): Diccionario Geográfico-Estadístico-Histórico de España: Granada. Salamanca, Sub Fuente Vaqueros, afirma que en I 827 una inundación cambió el cauce del Genil que pasó desde entonces por el sur de Fuente Vaqueros.

43 Ver gráfico 2. Alquerías de la Vega. Grupos según pago de alcabalas. 


\section{ANÁLISIS HISTÓRICO}

Después de habernos aproximado a la naturaleza de las fuentes documentales y de haber establecido unas premisas básicas que nos permitan su análisis nos proponemos sacar de ellas el mayor partido. Para ello vamos a dividir el estudio en dos partes: la primera concierne a la estructura económica y de poblamiento de la Vega, la segunda a la comparación de la comarca con las vecinas para hacernos una idea sobre las circunstancias en que se encontraba el centro del reino de Granada tras la conquista.

\section{I LA VEGA DE GRANADA}

Sabemos que la situación de la comarca granadina a inicios del XVI no era muy favorable. Tras ocho años de dominio castellano los mudéjares se habían convertido en masa tras la infructuosa revuelta de la Navidad de 1499. La estructura de poblamiento tradicional se había visto afectada con el establecimiento de Santa Fe en el centro del territorio, el despoblamiento y abandono de las propiedades durante la guerra, la emigración de parte de los vencidos y la confiscación de bienes (hábices, propiedades de sublevados y los términos de Güéjar y Pinillos enteros) después de la rebelión mudéjar. Tampoco la coyuntura agrícola era buena: mala cosecha en I50| (LUNA DíAZ, J.A., 1979, p. 24I), posiblemente repetida en 1503,44 sequía y mala cosecha en todo el reino de Granada durante 1506 (BERNÁLDEZ, A., 1962, p. 515 y ss.) y las consiguientes subidas de precios. ${ }^{45}$

Con la conversión también cambió el sistema fiscal de los mudéjares. Se establecen los impuestos castellanos sobre la población morisca y se anulan los tradicionales nazaríes (LADERO, M. A., 1976, p. 195). Creemos que además hubo una reorganización de los partidos fiscales. Si comparamos los establecidos para los impuestos de las alquerías en 1495 y las alcabalas de estas mismas desde I50 I a I503 hallaremos que concuerdan bastantes localidades en ambos documentos. Pero hay algunas como el Godco, Ansola, Iznalloz, Casteldeferro y Albuñol que sólo figuran en 1495. En este año, además, el término rural de la ciudad debió dividirse en varios partidos con los nombres de Zaydín, Trasguadatafir, Dixar Alqueran, Aux Arrambla, Laquemau, Mehelu y Mardanix.46 Algunos de ellos aún no están identificados pero podrían corresponder a nombres de lugares próximos a la ciudad. ${ }^{47}$

En este contexto se enmarcan las alcabalas y los diezmos. La interpretación de estos impuestos nos sirve para conocer la estructura económica de la región pero también indirectamente la estructura poblacional. Si intentamos establecer una equivalencia entre la riqueza de los lugares y su número de habitantes, ésta es posible en líneas generales. En la Vega las poblaciones que más rentas pagan, excepto Santa Fe, coinciden con aquellas que tenían más mezquitas, hornos y barrios según los libros hábices de 1505. ${ }^{48}$ Los inventarios de hábices son traducciones de libros anteriores escritos en árabe, así que podrían reflejar una situación anterior a la conquista. Pero si analizamos además las parroquias y anejos creados en 1500 por la Bula de Erección comprobamos que los lugares con iglesia parroquial suelen pagar más alcabala que sus anejos. Asimismo las alquerías/parroquias que pagan más en toda la comarca abarcan con sus anejos un área más reducida que las contribuyentes con cantidades más

\footnotetext{
44 Alcabalas de 1503. "esta por arrendar las ventas que como esta el canpo perdido no se halla nada por ellas"

45 LUNA DIAZ, J A., 1979, ps. 243-244. DE LA OBRA, J. M., 1986, doc. I 32 un campesino se asocia con otros para comprar la sembradura, dada su carestía, para sembrar un cortijo que ha tomado en arrendamiento. Zafayona, 1507.

46 A.G.S. Exp. Hac. L. 12. Arrendamiento de las rentas que entran en el partido de diezmos y alquerías de Granada de I.495 (28-3-I496).

47 Cft. JIMENEZ MATA, Mª C., 1990. El Zaydín y Laquemau existen todavía, este último con el nombre de la Camaura. Trasguadatafir creemos que puede ser un toponimo derivado de Tafiar. Aux Arrambla debería constituir un territorio cercano a la puerta de Bib Arrambla y Mardanix correspondería a la Cudia Ebn Mardanis de los alrededores de Granada citada por Simonet en su Descripción del Reino de Granada p. 135.

48VILLANUEVA, Ma C., 196I. Relación de 1505. Veanse Güéjar, La Zubia, los Ogíjares o Alhendín. Los bienes hábices en la parte oeste de la Vega no fueron respetados ni inventariados por lo que no tenemos noticias sobre ella.
} 
bajas. ${ }^{49}$ No obstante, esta relación entre riqueza y población no puede ser totalmente directa siempre porque hay otros factores que la alteran. Granada capital debe estar mucho más poblada porque sus habitantes no dependen sólo del campo sino también del comercio y de la administración. De la misma manera puede haber alquerías con poca población pero con mesones u otros negocios que pagan una renta importante.

En líneas generales podemos observar en el cartograma 3 de la Bula de Erección que la organización de los lugares se hace siguiendo los cauces fluviales o entre ellos, esto es más notorio en las zonas de sierra, pero también se puede observar en las cuencas del Dílar, Monachil, Genil y Cubillas. En cambio en el norte no se da este fenómeno porque no hay ríos importantes que ordenen el poblamiento y parece más bien que los lugares están agrupados por cotas de altura y por su cercanía.

Está claro también que los lugares más poblados se apiñan en la cabecera de la Vega mientras que los existentes al oeste de Santa Fe tienen escasa riqueza y población. Tanto es así que las relaciones de alcabalas diferencian a estos llamándolos cortijos y califican de alquerías a los restantes. Además no debieron estar muy controlados por Granada ya que en 1503 algunos (posiblemente los más cercanos a lllora y Montefrío) fueron reclamados por los recaudadores de las villas como pertenecientes a ellas, aunque habían pagado con los demás lugares de Granada en los años anteriores. ${ }^{50}$ ¿Esta situación es consecuencia de la guerra y posterior conquista cristiana o viene de más atrás? Creemos que en gran parte es anterior a la conquista, si bien ésta no mejoró las cosas. La mayoría de los cortijos se asientan al este de Santa Fe y en torno o dentro del Soto de Roma, una zona pantanosa en la encrucijada de los ríos Cubillas y Genil. Era frecuente hasta el siglo pasado que el río Genil tuviera crecidas y se desbordara (MADOZ, P., 1987, p. 83). Junto a ello, la humedad del Soto podía causar enfermedades como ocurría en Santa Fe (LADERO M. A., 1968, p. 534). Todo lo anterior no haría de esta parte de la Vega un lugar muy propicio para una organización agrícola desarrollada ni para el asentamiento. Es curioso que el reparto musulmán de las aguas del río Genil sólo llegase hasta la alquería del Godco (después Santa Fe) (GARRIDO ATIENZA, M., I893, p. I I) y que la mayoría de las poblaciones más allá de ésta fueran propiedad de la Corona Nazarí (IIMENEZ MATA, Ma C., 1990), en cuyo tiempo se plantó numeroso arbolado y se repartieron sus tierras entre muchos colonos según noticia de Pascual Madoz (MADOZ, P., 1987, Sub Soto de Roma). Esta situación no mejoró con la conquista. La población musulmana debió de huir ante el avance cristiano y un área tan extensa no facilitaría la repoblación, cuando además los cristianos preferían concentrarse en los núcleos urbanos. Gran parte de los cortijos cayeron en manos de la nobleza (CORTES, A. Y VINCENT, B., 1986, Tomo III, p. III) y desde I 499 el Rey Católico convierte el Soto en cazadero real vedando la caza en sus términos. ${ }^{51}$ Por todo esto es bastante posible que la dominación cristiana mantuviera una poblacion escasa y preservara el territorio de las rozas que se practicaron en otras partes del reino (MALPICA, A., 1981, p. 225). Aunque, por otro lado, el gran ascenso del pago de alcabalas (un $813 \%$ de $150 \mid$ a |503) experimentado por todos o parte de estos lugares denotaría un aumento de su actividad económica (aún por determinar) lo que no significa necesariamente que aumentaran sus habitantes.

El Cartograma I y el gráfico 2 revelan que el tipo más abundante de alquería (un $74 \%$ del total) es el que paga menos alcabala (entre 0 y 9.999 mrs.). El panorama que nos presenta este dato es el de una población dispersa en numerosos lugares pequeños (nor-

\footnotetext{
49 SIMONET, F. J.: Descripción del reino de Granada ... p. I 37. Ver en el cartograma 3, por ejemplo, las áreas que abarcan las parroquias de La Zubia o los Ogíares y las de Cogollos o Pulianas.

50 Alcabalas de 1501, I502 y 1503

51 Soto de Roma (Fuentevaqueros) según las respuestas del Catastro de Ensenada. Editores Tabapress, Ayuntamiento de Fuente Vaqueros y Centro de Gestión Catastral y Cooperación Tributaria. Madrid. 1990, p. 22 y ss.
} 
malmente con una mezquita y un horno) situados sobre todo al este de la Vega en la llanura o estribaciones de la sierra, poblaciones que seguramente se organizarán en grupos dispuestos alrededor de núcleos más ricos. Por otro lado la acumulación de los lugares más prósperos y poblados es semejante en los cartogramas de alcabalas y diezmos, aunque haya de tres a cinco años de diferencia entre ambos y sean impuestos diferentes. Estos lugares son, junto con la ciudad y Santa $\mathrm{Fe}$, las alquerías del sur de Granada instaladas desde el piedemonte de la Sierra hasta el valle del Genil. El cartograma de los diezmos nos describe un trapecio cuyos vértices corresponden a Granada ciudad, La Zubia, Alhendín y Santa Fe. Algo parecido nos muestra el cartograma más preciso de las alcabalas destacando La Zubia y Alhendín y, por debajo, los Ogijares, Gabia Grande, Churriana, Gójar y Otura. Por tanto los lugares más productivos se sitúan en una zona baja (entre 600 y 800 metros) regada por los ríos Genil, Monachil y Dilar y que debió ser la vía tradicional de comunicación entre Granada capital y la costa. Curiosamente negocios tales como carnicerías, mesones o tiendas, que pagaban la alcabala aparte del alquería, suelen figurar con más frecuencia en estos lugares. Así ocurre en Gabia Grande, la Zubia, Ogíjares, Alhendín y Churrriana. Hay algunas excepciones como La Malá, Beas y Alfacar. Estos negocios tienen un gran peso específico en el total pagado por el lugar. ${ }^{52}$ Hay otras poblaciones o grupos de poblaciones de cotización alta, pero no tan apiñadas como en la parte sur de la capital y, en su mayoría, bastante alejadas de ésta. En el cartograma de las alcabalas destacan Pinos Puente, Albolote y Maracena, Cogollos, Alfacar y Víznar y, adentrada en Sierra Nevada, Güejar; en los diezmos figuran sobre todo Pinos Puente y Güéjar.

Como ya dijimos la cotización global por alcabala en toda la Vega aumenta en un 107 $\%$ desde $150 \mid$ a $1503 .{ }^{53}$ Pero un lapso de tres años resulta escaso para analizar los cambios sufridos por una comarca en una época no caracterizada precisamente por la estabilidad. De ahí que sólo debamos prestar atención a los casos más extremos. Los pueblos que más han aumentado su cotización de I50 I a I503 son los cortijos de Granada con un $813 \%$ de incremento, Güéjar (553\%), Darabenaroz (525\%), Beas (203\%) y Escúzar (197\%). Mientras que los que han experimentado una subida menor son Cújar (20\%), Ambroz (28 \%), Peligros (4I \%) y Hotallar (44 \%)..$^{44}$ Como vemos son lugares muy distantes unos de otros, lo que indica que no son fenómenos propios de una zona específica.

Por las razones anteriores sólo nos permitimos aventurar algunas explicaciones para ciertas poblaciones concretas. Tanto los cortijos de Granada como Darabenaroz pudieron aumentar su aportación por una mejora de sus condiciones o por una estimación baja de los arrendadores del cobro que fue subiendo en los años siguientes. No olvidemos que Darabenaroz era una población compuesta por varios cortijos diseminados (HERNÁNDEZ BENITO, P., 1991, p. 61) y que la implantación de las alcabalas en la comarca granadina se hace a partir de 1500. En cuanto a Güéjar y Pinillos se sublevaron en 1499 y tuvieron que ser tomadas militarmente, la Corona expropió casi la totalidad de las dos alquerías (el $94 \%$ en Güéjar y el 82 \% en Pinillos) y la mayoría de la población fue vendida como esclava (HERNÁNDEZ BENITO, P., 1990, ps. 19, 20 y 95). Desde 1500 a 1504 la Corona arrendó las tierras, pero en diciembre de 1504 los Reyes deciden darlas en censo a un particular que las subencensaría a colonos (creemos que mudéjares) porque así se poblarían mejor y se acrecentarían las alcabalas y tercias reales (HERNÁNDEZ BENITO, P., 1990, p. 109). El particular es Fernando Díaz de Puebla y se le pone como condición del censo enfitéutico que instale entre los dos lugares I 50 vecinos y que no adehese sus términos. Pero en febrero de 1505 el Rey Fernando acepta una puja del Ayuntamiento de Granada a instancias de éste, que estaba

\footnotetext{
52 Ver gráfico 5.

53 Ver gráfico I.

${ }^{54}$ Ver cuadro I.
} 
muy interesado en administrar las alquerías ${ }^{55}$ y que conserva el censo hasta que consigue la propiedad en tiempos del emperador Carlos (BIRRIEL SALCEDO, M., 1979, ps. 133 y 135). Parece que el sistema funciona bien, al menos hasta I506, en que Güéjar es una de las poblaciones más productivas según sus diezmos. Otro caso, el de Escúzar, va unido al de la Malá y todo el Quempe. La región sufrió una despoblación casi total al final de la guerra e inmediatamente después de la conquista sólo estaban pobladas La Malá y Escúzar. Así figura en la información que solicita en 1503 la Reina Isabel sobre los derechos que cobraban Bulcaçin el Muleh y Yuçaf Aben Comixa en el Quempe y que son concedidos por los Reyes al Monasterio de San Jerónimo desde $1495 .^{56}$ Pero poco a poco tanto la población como la producción rural fueron aumentando como demuestran las alcabalas de Escúzar y las de La Malá (ésta en menor medida). También según las declaraciones del testigo Juan de Mendoza en la información de la Reina Isabel los derechos del Quempe van aumentando de 1492 a 1496, excepto en el "segundo año" ( 1493 ) porque "se siembra y coje mas". De la misma manera el diezmo desde 1500 a 1503 se acrecienta salvo en $1500^{57}$ y en 1506 con un total inferior a $1503^{58}$. ¿A qué se debe este progreso general desde la conquista hasta I 503 por lo menos? A un aumento de los cultivos indudablemente, pero también a las rozas que se hacen en este periodo como declara la información sobre el Quempe: "... y como las alquerias e tierras del Quempe de cada uno año se pueblan y ronpen las tierras e se sienbran va creçido en el pan e diezmos de ganados segun que por esta ynformación Vuestra Alteza vera" 59
Existen también algunos datos sobre el grado de señorialización que experimentaron la Vega y sierras granadinas. La fortuna amasada por Hernando de Zafra a inicios del XVI y transmitida a sus sucesores es el primer caso. Hernando de Zafra acumuló por donación real o compra abundantes propiedades: Calicasas, Casis (término de Albolote) (SECO DE LUCENA, L., 1974, Sub Caxis), Tejutor, Arenales, Cortes y Huete, Cájar y Cacín todas al norte de la Vega menos las dos últimas (GARZON PAREJA, M., 1.974 - 1.975, ps. 137 -144). El lugar de Huete corresponde al actual Huetor Santillán y no a Huetor Vega como afirmaba Garzón Pareja (Ibidem, p. I35), ya que su nombre es Huete según los documentos y no Huetor (JIMENEZ MATA, Ma C., 1990, sub Wâd, LADERO, M. A., 1969, ps. 355 - 424). Asimismo Cortes es un pueblo situado entre los términos de Granada ciudad, Beas, Dúdar y Huétor Santillán que aún en la segunda mitad del XVI era propiedad de los sucesores de Hernando de Zafra (GARZÓN PAREJA, M.,I.977, p. 67). Las alquerías de Huete y Tejutor no pagan rentas reales desde I 495 hasta 1503 por lo menos, aunque no sabemos si esta cantidad se la embolsaba Zafra por algún privilegio como ocurría en su señorío de Castril ${ }^{60}$. Parece que el poder ejercido por Hernando de Zafra en la ciudad y como representante de los Reyes libró a ciertas propiedades suyas del pago de impuestos. En 1503 el Rey manda que en la alquería de Huete, propiedad de Zafra, no se cobre alcabala y se le perdonan al arrendador del cobro 20.000 mrs. por ella ${ }^{61}$. Si observamos las cotizaciones medias de la Vega Huete debió ser un lugar de cierta importancia. Hacia 1500 también Zafra entra en conflicto con los vecinos de Granada y alquerías cercanas por no

\footnotetext{
55 Archivo Municipal de Granada. "Propios" Leg. I, sin foliar.

56A.G.S. Cámara de Castilla. Pueblos. Leg. 8 - 276. Declaración del testigo Juan de Mendoza. Este documento ha sido estudiado antes en TRILLO SAN JOSE, C.: "Fiscalidad mudéjar en el Reino de Granada: las rentas del Quempe" Ver Nota I.

57 Si calculamos las fanegas entregadas incluso a los precios mínimos que les puso el Ayuntamiento de Granada en I500 (70 mrs. la de trigo y 60 la de cebada). Cft. LUNA DIAZ, J. A., 1979, p. 243. Para las fanegas y cantidades pagadas en el Quempe cft. TRILLO, C., 1992, p. 864 y 865

58 Ver cuadro II, en I506 La Malá y su partido pagan 128.939 mrs. y en I 503 | 45.800 mrs y 450 fanegas de pan terciado por todos los diezmos. Cft. TRILLO SAN JOSE, C.,1992, p. 865.

59 A.G.S. Cámara de Castilla. Pueblos. Leg. 8 - 276. Ultima hoja del documento.

60 A.G.S. Exp. Hac. L. 12. Arrendamiento de las rentas que entran en el partido de diezmos y alquerías de Granada de I.495 (28-31496). Y Alcabalas de I50 I, I 502 y I503. Y GARZON PAREJA, M.: "Hernando de Zafra ..." ps. I39.

61 Alcabalas de 1503.
} 
respetar los usos de pastos y rozas comunales establecidos desde época nazarí en los lugares de Alfacar, Huete, Tejutor, Arenales, Cortes y Cubillas. ${ }^{62}$ A pesar de todo Huete y Cortes pagan los diezmos y es curioso que, pagando una cantidad pequeña, formen un partido independiente.

Lo mismo ocurre con los diezmos de Beas de Granada, propiedad de la familia BobadillaPeñalosa; este lugar sí paga alcabala (HERNÁNDEZ BENITO, P., en prensa). Los Bobadilla tenían también numerosas propiedades en Pinos Puente. En I50 I se valoró aparte de la alquería lo que debían pagar de alcabala (500 mrs. un 3'6\% de todo el lugar) pero no se pagó al final según la relación. ${ }^{63}$ Hay lugares de la familia que no figuran en las relaciones de alcabalas como Cijuela, Ainalabrax, la Torre de Roma y Bordonal (bidem.), pero que deben estar dentro de un partido en los diezmos. En 1544 consta que los cortijos de Láchar, Cijuela, Torre de Roma y Chauchina lo pagaban y estaban sujetos al fuero de Santa Fe (MORENO TRUJILLO, Ma A., 1986, Documento I234). En general no parece haber propiedades señoriales cuyo titular recoja el impuesto. Por ejemplo Juzeila, Daragoleja, Daimucejo y Tocón son propiedad del duque de Sessa y pagan alcabala (CORTES PEÑA, A. y VINCENT, B., 1.986, p. I I I). Otras noticias también importantes de acumulación de lugares y tierras son las concernientes a los Mondéjar (lbidem, p. | |3), la propiedad real del Soto de Roma y las concesiones hechas al arzobispado y órdenes religiosas. ${ }^{64}$ Por todos estos datos creemos que gran parte de las zonas periféricas al centro de la Vega quedaron en manos de la Corona, la oligarquía urbana, la nobleza y la Iglesia mediante concesión o compra en una proporción bastante considerable. Aunque si consideramos que no hay señorío de hecho hasta que los impuestos y el diezmo eclesiás- tico son recogidos para el señor, la mayoría de las tierras son sólo propiedades y no señoríos jurisdiccionales.

\subsection{LA VEGA DE GRANADA Y SUS COMARCAS VECINAS}

Gracias a los diezmos de 1506 podemos ahora extraer algunas conclusiones acerca de la producción rural en la Vega de Granada y compararla con las regiones vecinas. Como vemos en el cuadro III Granada y sus alquerías constituyen la Región más productiva con diferencia, también es cierto que es la más extensa. Después de ella figuran Loja y sus alquerías, Iznalloz, Alhama y su región y finalmente las villas de la Vega. Sólo en la Vega de Granada y las comarcas de Loja y Alhama es posible establecer una comparación, pues los datos diferencian en ellas el centro de la comarca de los lugares que la integran y, además, tenemos cuenta detallada de los apartados de la renta en las ciudades. ${ }^{65}$ Si observamos el cuadro IV veremos que en la Vega es más importante la producción total de las alquerías y Santa Fe (casi un 70 \%) frente a la de Granada capital. En cambio en Loja y Alhama es a la inversa, la ciudad es más importante que todos los lugares de la región, caracterizados por su escaso número. Esto es debido seguramente a que los lugares dependientes de Granada cubren una extensión mucho mayor que los de Loja o Alhama. A pesar de todo en las tres áreas la ciudad es el núcleo más productivo de todos los lugares de su circunscripción. ${ }^{66}$ También es de destacar que las villas de Granada no superan los diezmos pagados por algunas alquerías. Así la villa que más cotiza (Iznalloz) paga menos que el partido de Pinos Puente y más o menos lo mismo que los de Churriana o la Zubia. ${ }^{67}$ Por lo que respecta a las ciudades Granada paga mucho más que Loja o Alhama. Teniendo en

62 A.G.S. Cámara de Castilla. Pueblos. Leg. 8 - 283.

63 Alcabalas de 1501.

64 Por ejemplo las tierras y rentas de los jerónimos en el Temple y Sierra Nevada. Cft. TRILLO SAN JOSE, C.: "Fiscalidad mudéjar en el Reino de Granada...", p. 860.

65 Ver cuadro II.

66 Ver cuadro VI donde se demuestra esta afirmación para Granada.

67 Ver cuadro II 
cuenta que los términos municipales no han debido cambiar mucho desde el XVI, Granada tiene menos territorio que Loja y Alhama y una producción mucho mayor. ${ }^{68}$

Si atendemos a las características de la producción rural sólo podemos analizarlas en las ciudades, aunque son ejemplos significativos, ya que pagan un porcentaje bastante alto del diezmo de sus respectivas comarcas. ${ }^{69}$ Granada, Loja y Alhama presentan dos aspectos comunes. En primer lugar el predominio de la agricultura y, especialmente del cereal. En las tres ciudades el pan representa más del $70 \%$ de todos sus diezmos. ${ }^{70}$ En segundo lugar dentro de la ganadería, menos importante que la agricultura, el animal más abundante es la oveja, con unas cantidades que superan por lo menos en un $100 \%$ a las de ganado vacuno. ${ }^{71}$ Ignoramos si las cabras entraban dentro del capítulo de los corderos y por qué razón no se menciona a los cerdos. Junto a estos aspectos comunes se dan también notorias diferencias entre las ciudades. Mientras que en Granada el segundo capítulo después del cereal es la hortaliza (12'2\% del total de la ciudad), en Loja y Alhama es la renta de los corderos (entre un 12 y un $15 \%$ ). Además Loja y Alhama superan en valores absolutos a Granada en ganadería lanar y vacuna. Granada, a su vez, está muy por encima en la

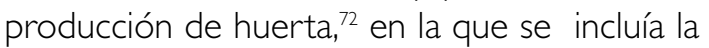
producción de los cármenes. ${ }^{73}$ En corderos Loja dobla la cantidad pagada por Granada. ${ }^{74}$ Cabe pensar que la Vega granadina tuviera centros ganaderos más importantes que la capital, posiblemente en el Soto de Roma y los pastos comunes de que cada alquería disponía y que podían ser usados por los vecinos de la ciudad. ${ }^{75}$ Por otro lado dentro de las rentas de Loja destaca el papel del vino (I $0^{\prime} 7 \%$ del total frente al 6'5\% de Granada), el lino (I $\%$ frente al 0'4 \% de Granada) y la miel que sólo figura como capítulo en esta ciudad. La importancia que tenía en Loja la apicultura en áreas de monte bajo es confirmada por otros estudios. ${ }^{76}$ En Alhama tiene importancia relativa el vino (5'9 \% frente al 6'5\% de Granada) y el ganado vacuno cuya cotización en términos absolutos es, también, superior a las de Granada y Loja; debemos abrigar reservas hacia este último dato porque en la renta de los becerros van incluidas otras minucias sin especificar. La producción sedera parece ser monopolio de Granada pues no se declara ni en Loja ni en Alhama. ${ }^{77}$ En cuanto a los pollos sólo aparecen en Loja y Granada siendo su importancia escasa.

De todo lo aquí expuesto parece inducirse que Granada se diferencia de Loja y Alhama sobre todo en el mantenimiento de la población musulmana y la menor importancia de su repoblación, que implantó en éstas un diferente modelo agrario (con un predominio del cultivo de cereal y viña y explotación ganadera) y de poblamiento (exclusivamente castellano y concentrado). Puede que este retrato robot de la situación estuviera determinado también por circunstancias previas como las dificultades de poblamiento durante la guerra y la expulsión de la población musulmana en

\footnotetext{
68 Diezmo de todos los productos de Granada 1.437 .742 mrs., Loja 619.068 mrs. y Alhama 197.802 mrs. Un dato que demuestra el mantenimiento de los términos es que en 1510 el diezmo de las huertas de Granada ciudad se recogía hasta el límite entre ésta y Santa Fe, Cft. OBRA SIERRA, J M Ma de la. Catálogo de Protocolos Notariales... Docs. n I.640 y I.242. Para la extensión de los términos municipales cft. Gran Atlas Enciclopédico El Mundo del Siglo XXI Planeta De Agostini (ed.) Barcelona. 1993. Granada (88 Km cuad.), Alhama (398 km. cuad.) y Loja (454 Km cuad.).

69 Ver cuadro IV.

70 Ver cuadro $\mathrm{V}$

7I Ver gráfico 4.

72 Ver gráfico 3

73 OBRA SIERRA, J. Mª, 1986, Docs. n 1.640 y 1.242, en éste se arrienda el diezmo de las huertas y cármenes de Granada excepto algunas huertas (¿las reales?), el haba y el garbanzo.

74 Ver gráfico 4

75 A.G.S. Cámara de Castilla. Pueblos. Leg. 8 - 283.

76 Ver cuadro V y MALPICA CUELLO, A.: El Concejo de Loja ... ps. 28 I - 282.

77 Ver gráfico 4 y cuadro ॥
} 
Alhama (LADERO QUESADA, M. A., 1968, p. 539), o la escasez de huertas en Loja después del primer repartimiento. A la vez que, también en Loja, el acaparamiento de las tierras cultivables por grandes propietarios y el trato preferente para los ganaderos forzó un repartimiento de rozas entre los pequeños agricultores de 1506 a 1508.78 Esta misma diferencia se puede establecer entre las villas de Granada y las alquerías más pobladas de la Vega. En la Vega el asentamiento de la población castellana y la aplicación de sus prácticas agrícolas también se hizo, sobre todo en Santa Fe y en las grandes propiedades, pero la abundante población musulmana preexistente supondría un obstáculo importante.

\section{CONCLUSIONES}

Como hemos visto gracias al análisis de documentación fiscal podemos deducir algunas conclusiones generales sobre la Vega de Granada. Tenemos un conocimiento aproximado de las rentas de las alcabalas y los diezmos. Aunque la falta de nociones exactas, particularmente en las alcabalas, limitan el valor de las consideraciones sobre poblamiento que hemos realizado. A pesar de ello creemos haber demostrado que es posible el análisis estadístico de estas fuentes y que mantienen una relación muy directa con el poblamiento. Las enseñanzas concretas que conseguimos son abundantes. En primer lugar los lugares más poblados se apiñan en la cabecera de la Vega mientras que los existentes al oeste de Santa Fe tienen escasa riqueza y población a inicios del s. XVI. El poblamiento predominante es el de núcleos pequeños en torno a uno más importante. Parece además que la cantidad de tierras granadinas en poder de los castellanos, y sobre todo de su clase dominante, era muy considerable. Finalmente existen diferencias notables entre la Vega granadina y las comarcas de Loja y Alhama, diferencias derivadas de la expulsión o no de la población musulmana. En las zonas repobladas por los cristianos se da un modelo de ocupación y explotación diferente a aquellas en las que se mantenía, aunque parcialmente, el modelo anterior representado por los mudéjares.

\section{BIBLIOGRAFÍA}

ACIÉN ALMANSA, M. (1979): Ronda y su Serranía en tiempo de los Reyes Católicos, Málaga

BERNÁLDEZ, A. (1962): Memorias del reinado de los Reyes Católicos. Real Academia de la Historia. Madrid

BIRRIEL SALCEDO, M. (1979): "Notas sobre la Hacienda Municipal de Granada en el primer tercio del siglo XVl" Chronica Nova

CORTES PEÑA, A. y VINCENT, B. (1.986): "La época moderna, siglos XVI, XVII y XVIII", en Historia de Granada, tomo III, Granada

DE LA OBRA SIERRA, J. M. (1986): Catálogo de Protocolos Notariales: Granada 1505-15/5 Tesis doctoral leída en la Universidad de Granada en marzo de 1986. Existe una edición parcial publicada por la Universidad

GARCÍA VALENZUELA, H. (1988): Índices de los Libros de Cabildo del Archivo Municipal de Granada. 1497 I 1518, Granada

GARRIDO ATIENZA, M. (I 893): Los alquezares de Santa Fe. Granada,

GARZÓN PAREJA, M. (1974): Diezmos y tributos del clero de Granada, Granada.

GARZÓN PAREJA, M. (1.974-|.975): "Hernando de Zafra, cortesano y hombre de empresa de los Reyes Católicos" Cuadernos de Estudios Medievales. II-III

GARZÓN PAREJA, M. (1.977): "Cortijos del término de Granada que pertenecieron a moriscos", Cuademos de la Alhambra, 13

HERNÁNDEZ BENITO, P. (1990): La Vega de Granada a fines de la Edad Media según las rentas de los Hábices, Diputación Provincial de Granada. Granada

HERNÁNDEZ BENITO, P. (199|): "Toponimia y poblamiento en la Vega de Granada en época medieval" Revista del Centro de Estudios Históricos de Granada y su Reino 5, ps. 6I-64

HERNÁNDEZ BENITO, P. (en prensa): "La ocupación territorial del Reino de Granada y el linaje de los Bobadilla y Peñalosa" Revista del Centro de Estudios Históricos de Granada y su Reino

JIMÉNEZ MATA, Ma C. (1990): La Granada Islámica. Univ. de Granada y Diputación Provincial de Granada. Granada

78 MALPICA, A., 1985, Para la escasez de huerta y olivar p. 174, para las rozas p. 225 y para la ganadería ps. 284-285. 
LADERO QUESADA, M. A. (1967): "La Hacienda castellana de los Reyes Católicos" Moneda y Credito I03 ps. 8I-88

LADERO QUESADA, M. A. (1968): "La repoblación del Reino de Granada anterior al año I500" Hispania, I I0

LADERO QUESADA, M. A. (1969): "Mercedes reales anteriores al año 1500", Hispania, I I2, ps. 355-424

LADERO QUESADA, M.A. (1973): La Hacienda Real de Castilla en el s. XV. La Laguna, Tenerife. .

LADERO QUESADA, M. A. (I 989): "El señorío de Lepe y Ayamonte a finales del s. XV: Mayorazgo. Valor y Rentas" en Los Mudéjares de Castilla y otros estudios de Historia Medieval Andaluza, Granada

LAPRESA MOLINA, E. (1979): Santafé: Historia de una ciudad del siglo XVI. Granada

LOPEZ DE COCA CASTAÑER, J. E. (1979): "Privilegios fiscales y repoblación en el reino de Granada (1485I520)" Baetica 2 (I) , ps. 205 - 223.

LÓPEZ DÍAZ, ISABEL (1992): "Las Alpujarras en la Hacienda Castellana de 1552" en IV Simposio Internacional de Mudejarismo: Economía. Teruel (1987). Diputación Provincial de Teruel y Gobierno de Aragón, Teruel, ps. 39-63.

LÓPEZ, T. (1990): Diccionario Geográfico de Andalucía: Granada. SEGURA GRAÍÑO, C. y DE MIGUEL, J. C. (editores). Granada

LUNA DÍAZ, J.A. (1979): "Apuntes para el estudio de la agricultura de Granada y su tierra en los primeros años de la conquista" Chronica Nova, ps. 231-248.

MADOZ, P. (1987): Diccionario Geográfico-EstadísticoHistórico de España: Granada. Salamanca

\section{RESUMEN}

El presente trabajo intenta analizar la evolución económica y del poblamiento de la Vega de Granada a fines de la Edad Media, cuando los castellanos han conquistado el Reino Nazarí. A través de la implantación del sistema tributario cristiano en la región obtendremos algunas conclusiones sobre este proceso. Para ello analizamos mediante procedimientos estadísticos diferentes relaciones de impuestos reales y eclesiásticos

PALABRAS CLAVE: Vega, Poblamiento, Alquería, Alcabala, diezmo, Tercias, Minucias
MALPICA CUELLO, A. (198I): El Concejo de Loja (I 486 -1508), Universidad de Granada, Granada

MALPICA CUELLO, A. Y TRILLO SAN JOSÉ, M. C. (|99|): "Fiscalidad y poblamiento de la tâ'a de Marchena" en Homenaje al Profesor Jacinto Bosch Vilá, Granada, vol. I, ps. 247-260

MORENO TRUJILLO, Ma A. (1986): Los protocolos notariales más antiguos de Santa Fe (15/4 - 1549). Análisis y Catálogo, Tesis leída en la Facultad de Filosofía y Letras de Granada. Hay una edición parcial de la Universidad de Granada

RAMOS IBASETA, J. R. (1988): Política ganadera de los Reyes Católicos en el Obispado de Málaga. Málaga

SECO DE LUCENA, L. (1974): Topónimos árabes identificados. Universidad de Granada. Granada

SIMONET, F. J. (I.872): Descripción del reino de Granada bajo la dominación de los naseritas. Granada

SUBERBIOLA MARTÍNEZ, J. ( $.974-75)$ : "Fisco, franquicias y problemas en la repoblación de Málaga (siglos XV XVI)" Cuadernos de Estudios Medievales II-III, ps. I49-196.

TRILLO SAN JOSÉ, M. C. (1992): "Fiscalidad mudéjar en el reino de Granada: las rentas del Quempe" Anuario de Estudios Medievales 22, ps. 853-878.

TRILLO SAN JOSÉ, C. (en prensa): "Modificaciones castellanas en la ciudad de Granada a fines de la Edad Media. El control del comercio" Revista del Centro de Estudios Históricos de Granada y su Reino

VILLANUEVA RICO, Ma C. (I.96I): Hábices de las mezquitas de la ciudad de Granada y sus alquerías. Madrid

\section{ABSTRACT}

In this work we will be analyzing the changes in the economy and in the characteristics of settlements in the Vega of Granada, at the end of Middle Ages, after the conquest of the muslim Kingdom by Castilla. The study of the tax system introduced in the area by the castilians will allow us to come to some conclusions about those changes. In this case, we will be analyzing trough statistical means several royal and ecclesiastical taxes.

KEY WORDS: Vega, Settlements, Alquería or Village, Alcabala, Tithe, Tercias, Minucias 
CUADRO I

ALCABALAS DE LAS ALQUERIAS DE GRANADA

\begin{tabular}{|c|c|c|c|c|c|}
\hline LUGARES & $|50|$ & 1502 & 1503 & MEDIA & AUMENTO \% \\
\hline Albolote & 20.191 & 28.000 & 37.600 & 28.597 & 86 \\
\hline Alfacar & 20.216 & 30.875 & 38.200 & 29.764 & 89 \\
\hline Alhendín & 30.000 & 40.338 & 60.000 & 43.446 & 100 \\
\hline Atarfe & 5.400 & 8.000 & 12.100 & 8.500 & 124 \\
\hline Beas & 2.700 & 8.000 & 8.200 & 6.300 & 204 \\
\hline Cenes & 2.700 & 3.150 & 4.800 & 3.550 & 78 \\
\hline Cogollos & 7.800 & 11.000 & 16.800 & 11.867 & 115 \\
\hline Cújar & 1.875 & $2.062 *$ & 2.250 & 2.062 & 20 \\
\hline Churriana & 12.750 & 18.500 & 27.800 & 19.683 & 118 \\
\hline Dílar & 5.850 & 9.000 & 13.500 & 9.450 & 131 \\
\hline Dúdar & 3.750 & $4.675 *$ & 5.600 & 4.675 & 49 \\
\hline Escúzar & 2.000 & 3.906 & 5.950 & 3.952 & 197 \\
\hline Gabia Grande & 21.000 & 27.000 & 38.000 & 28.667 & 81 \\
\hline Gabia Chica & 5.400 & 8.000 & 10.600 & 8.000 & 96 \\
\hline Gójar & 7.200 & 11.000 & 14.625 & 10.942 & 103 \\
\hline Güéjar & 3.400 & 17.000 & 22.200 & 14.200 & 553 \\
\hline Hotallar & 1.800 & 2.200 & $2.600 *$ & 2.200 & 44 \\
\hline Huetor Vega & 4.200 & 7.000 & 10.500 & 7.233 & 150 \\
\hline Malá y Temple & 6.600 & 5.600 & 10.660 & 7.620 & 61 \\
\hline Maracena & 8.8501 & 2.000 & 17.608 & 12.819 & 99 \\
\hline Ogíjares & 18.500 & $25.862 *$ & 33.224 & 25.862 & 79 \\
\hline Otura & 8.100 & 9.000 & 13.800 & 10.300 & 70 \\
\hline Peligros & 4.200 & 5.075* & 5.950 & 5.075 & 41 \\
\hline Pinillos & 810 & 1.000 & 2.062 & $1.29 \mid$ & 54 \\
\hline Pinos Puente & 13.669 & 20.000 & 29.572 & 21.080 & 116 \\
\hline Quéntar & 5.700 & 6.000 & 13.300 & 8.333 & 133 \\
\hline Víznar & 7.500 & 10.500* & 13.500 & 10.500 & 80 \\
\hline La Zubia & 30.500 & 40.000 & 52.700 & 41.06 & 772 \\
\hline Purchil & 2.250 & $2.989 *$ & 3.650 & 2.963 & 62 \\
\hline Belicena & 2.000 & $3.202 *$ & 4.320 & 3.174 & 116 \\
\hline Ambroz & 1.590 & $1.809 *$ & 1.980 & 1.793 & 24 \\
\hline SUMA TOTAL & & 8.000 & & & \\
\hline $\begin{array}{l}\text { Armilla grande / } \\
\text { Armilla chica }\end{array}$ & 3.000 & $4 .|4| *$ & 7.600 & 4.914 & 153 \\
\hline Darabenaroz & 480 & 1.359* & 3.000 & 1.613 & 525 \\
\hline SUMA TOTAL & & 5.500 & & & \\
\hline
\end{tabular}

- Las cantidades vienen expresadas en maravedís, excepto el aumento del impuesto desde I.50। a I.503 que es en tantos por ciento. - Los lugares están ordenados alfabéticamente, excepto los que pagaron algún año juntos, que van en la otra página.

- Las cantidades estimadas por nosotros van marcadas con un asterisco. 
CUADRO I (Continuación)

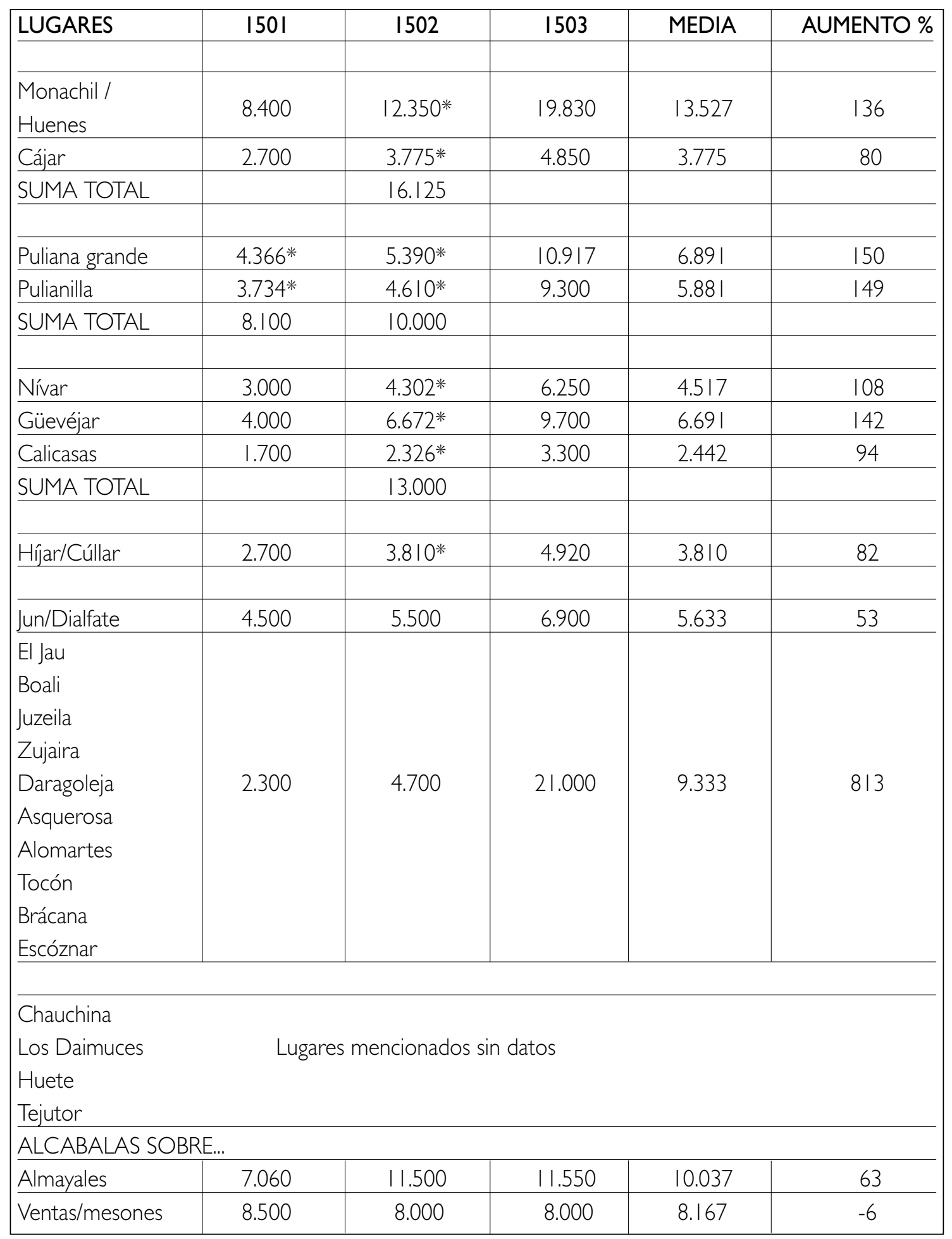

- Las cantidades vienen expresadas en maravedís, excepto el aumento del impuesto desde I.50 I a I.503 que es en tantos por ciento. - Los lugares están ordenados alfabéticamente, excepto los que pagaron algún año juntos, que van en la otra página.

- Las cantidades estimadas por nosotros van marcadas con un asterisco. 


\section{CUADRO II \\ DIEZMOS DE GRANADA Y SU ARZOBISPADO SIN LAS ALPUJARRAS Y VALLE DE LECRIN (I506)}

\begin{tabular}{|c|c|c|c|}
\hline LUGARES & TOTAL & PAN & RENTA EN MARAVEDIS \\
\hline \multicolumn{4}{|l|}{ GRANADA CIUDAD } \\
\hline Renta del Pan & 1.062 .752 & 604.916 & 457.836 \\
\hline Renta de los corderos & 33.921 & & \\
\hline Renta de los becerros & 8.320 & & \\
\hline Renta de la hortaliza & 176.800 & & \\
\hline Renta de los pollos & 4.011 & & \\
\hline Renta del vino & 94.080 & & \\
\hline Renta del lino & 6.469 & & \\
\hline Renta de la seda & 39.709 & & \\
\hline Ra. de los Alfahareros & 11.680 & & \\
\hline \multicolumn{4}{|l|}{ ALQUERIAS DE GRANADA } \\
\hline Huetor & 170.778 & 69.133 & 101.645 \\
\hline Güéjar y partido & 325.689 & 86.416 & 239.272 \\
\hline La Zubia & 288.437 & 120.983 & 167.454 \\
\hline Alhendín & 265.664 & 225.341 & 40.323 \\
\hline Dílar & $|57.74|$ & 69.133 & 88.608 \\
\hline Purchil & 239.617 & 120.983 & 118.634 \\
\hline Churriana & 294.166 & 138.266 & 155.899 \\
\hline Gabia & 204.183 & 120.98 & 383.200 \\
\hline Zafayona & 22.774 & 17.283 & 5.490 \\
\hline La Malá y partido & 128.939 & & \\
\hline Chauchina y partido & 116.416 & 86.416 & 30.000 \\
\hline Chauchina minucias & 11.880 & & \\
\hline Pinos Puente & 403.226 & 172.833 & 230.392 \\
\hline Atarfel & 63.116 & 51.850 & 111.266 \\
\hline Albolote & 115.053 & 82.653 & 32.400 \\
\hline Pulianas & 130.68 & 151.850 & 78.831 \\
\hline Cogollos & 119.200 & 51.850 & 67.350 \\
\hline Alfacar & 71.805 & 43.208 & 28.597 \\
\hline Huete y Corte & 38.868 & & \\
\hline Beas & 41.757 & & \\
\hline \multicolumn{4}{|l|}{ LOJA } \\
\hline Renta de los corderos & 78.100 & & \\
\hline Renta del pan & 434.489 & 434.489 & \\
\hline Renta de los becerros & 13.310 & & \\
\hline Renta de la hortaliza I & 6.549 & & \\
\hline Renta del lino & 6.000 & & \\
\hline Renta de la miel & 2.200 & & \\
\hline Renta de los pollos & 2.060 & & \\
\hline Renta del vino & 66.360 & & \\
\hline Huetor Tájar y partido & 197.802 & 138.266 & 59.536 \\
\hline Salar & 48.395 & 25.925 & 22.470 \\
\hline
\end{tabular}

- Las columnas Total, Pan y Renta van calculadas en maravedís 
CUADRO II (Continuación)

\begin{tabular}{|c|c|c|c|}
\hline LUGARES & TOTAL & PAN & RENTA EN MARAVEDIS \\
\hline \multicolumn{4}{|l|}{ ALHAMA } \\
\hline Diezmo de Alhama & 196.193 & 172.833 & 23.360 \\
\hline Renta de los corderos & 42.584 & & \\
\hline Renta del vino & 16.000 & & \\
\hline becerros, otras minucias & 18.099 & & \\
\hline Renta de Cacín & 34.139 & 17.283 & 16.856 \\
\hline \multicolumn{4}{|l|}{ VILLAS DE GRANADA } \\
\hline Santa Fe & 234.445 & 69.133 & 165.312 \\
\hline $\begin{array}{l}\text { Montefrío } \\
\text { Montefrío minucias }\end{array}$ & $\begin{array}{c}174.779 \\
16.016\end{array}$ & 69.133 & 105.646 \\
\hline Illora & 168.600 & & \\
\hline Moclín & 111.815 & & \\
\hline Colomera & 102.647 & & \\
\hline Colomera minucias & 7.000 & & \\
\hline $\begin{array}{l}\text { Iznalloz pan } \\
\text { Iznalloz minucias }\end{array}$ & $\begin{array}{c}277.626 \\
38.216\end{array}$ & & \\
\hline Almuñécar & 42.574 & & \\
\hline Salobreña y Motril & 33.720 & \multicolumn{2}{|c|}{ (cristianos viejos) } \\
\hline
\end{tabular}

- Las columnas Total, Pan y Renta van calculadas en maravedís

CUADRO III

IMPORTANCIA DE LAS DIFERENTES AREAS ESTABLECIDAS POR EL DOCUMENTO SEGUN EL PAGO DEL DIEZMO DE I506 (en tantos por ciento)

\begin{tabular}{|l|c|}
\hline AREAS & $\%$ \\
\hline GRANADA Y SUS ALQUERIAS & $66^{\prime} 6$ \\
\hline LOJA Y SUS ALQUERIAS & $12^{\prime} 2$ \\
\hline IZNALLOZ & $4^{\prime} 4$ \\
\hline ALHAMA Y CACIN & $4^{\prime} 3$ \\
\hline SANTA FE & $3^{\prime} 3$ \\
\hline MONTEFRIO & $2 ' 7$ \\
\hline ILLORA & $2 ' 3$ \\
\hline MOCLIN & $I^{\prime} 6$ \\
\hline COLOMERA & $I^{\prime \prime} 5$ \\
\hline ALMUÑECAR & $0^{\prime} 6$ \\
\hline SALOBREÑA Y MOTRIL (cristianos viejos) & $0^{\prime} 5$ \\
\hline
\end{tabular}

CUADRO IV

PARTICIPACION DE LAS CIUDADES Y SUS ALQUERIAS EN EL TOTAL DE LOS DIEZMOS DE CADA CIRCUNSCRIPCION I506 (en tantos por ciento)

\begin{tabular}{|l|c|c|c|}
\hline & GRANADA & LOJA & ALHAMA \\
\hline CIUDAD & $30^{\prime} 3$ & $71^{\prime} 5$ & 89 \\
\hline ALQUERIAS & $69^{\prime} 7$ & $28^{\prime} 5$ & 11 \\
\hline
\end{tabular}


CUADRO $V$

DIEZMOS DE I506: PORCENTAJES DE LOS DIFERENTES CAPITULOS DE LA RENTA EN LAS CIUDADES DE GRANADA, LOJA Y ALHAMA

\begin{tabular}{|l|c|c|c|}
\hline CONCEPTOS & GRANADA & LOJA & ALHAMA \\
\hline PAN & $74^{\prime} 4$ & $70^{\prime} 2$ & $7 I^{\prime} 9$ \\
\hline HORTALIZA & $12^{\prime} 2$ & $2 ' 7$ & - \\
\hline VINO & $6^{\prime} 5$ & $10^{\prime} 7$ & $5^{\prime} 9$ \\
\hline CORDEROS & $2^{\prime} 3$ & $12^{\prime} 6$ & $15^{\prime} 6$ \\
\hline BECERROS & $0^{\prime} 5$ & $2^{\prime} I$ & $6{ }^{\prime}\left(^{*}\right)$ \\
\hline POLLOS & $0^{\prime} 2$ & $0^{\prime} 3$ & - \\
\hline LINO & $0^{\prime} 4$ & 1 & - \\
\hline SEDA & $2^{\prime} 7$ & - & - \\
\hline ALFAHAREROS & $0^{\prime} 8$ & - & - \\
\hline MIEL & - & $0^{\prime} 4$ & - \\
\hline
\end{tabular}

(*) En Alhama figuran con los becerros otras minucias sin especificar

\section{CUADRO VI}

PORCENTAJE DE LOS LUGARES DE LA VEGA Y SIERRA DE GRANADA EN LOS DIEZMOS DE I506

\begin{tabular}{|l|c|}
\hline LUGARES & PORCENTAJES \\
\hline GRANADA & $28^{\prime} 9$ \\
\hline SANTA FE & $4^{\prime} 7$ \\
\hline HUETOR & $3^{\prime} 4$ \\
\hline GÜEJAR & $6^{\prime} 5$ \\
\hline LA ZUBIA & $5^{\prime} 8$ \\
\hline ALHENDIN & $5^{\prime} 3$ \\
\hline DILAR & $3^{\prime} 2$ \\
\hline PURCHIL & $4^{\prime} 8$ \\
\hline CHURRIANA & $5^{\prime} 9$ \\
\hline GABIA & $4^{\prime} I$ \\
\hline ZAFAYONA & $0^{\prime} 5$ \\
\hline LA MALA & $2^{\prime} 6$ \\
\hline CHAUCHINA & $2^{\prime} 6$ \\
\hline PINOS PUENTE & $8^{\prime} I$ \\
\hline ATARFE & $3^{\prime} 3$ \\
\hline ALBOLOTE & $2^{\prime} 3$ \\
\hline PULIANAS & $2^{\prime} 6$ \\
\hline COGOLLOS & $2^{\prime} 4$ \\
\hline ALFACAR & $I^{\prime} 4$ \\
\hline HUETE Y CORTE & $0^{\prime} 8$ \\
\hline BEAS & $0^{\prime} 8$ \\
\hline
\end{tabular}




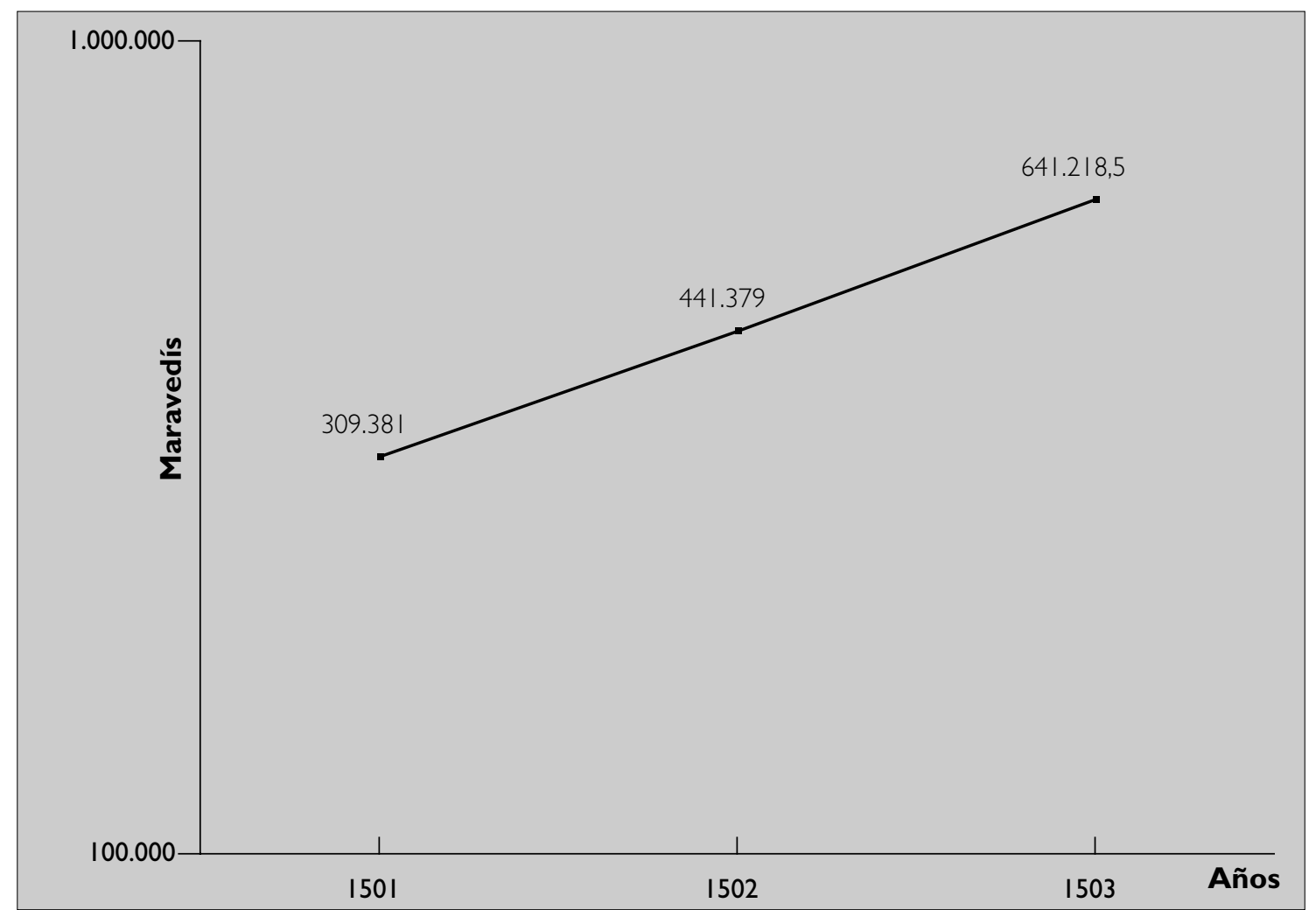

Gráfico I. Evolución de las alcabalas de las alquerías de la Vega

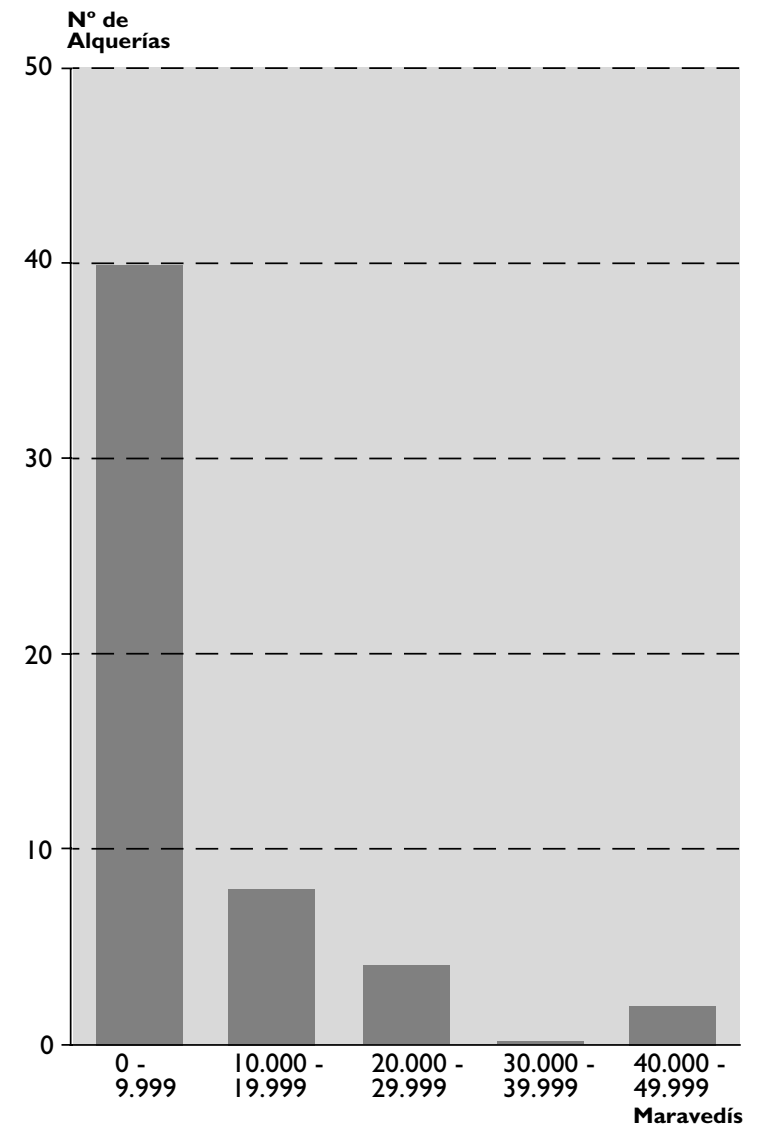

Media de las alcabalas de 1501,1502 y 1503

Gráfico 2. Alquerías de la Vega: grupos según pago de alcabalas

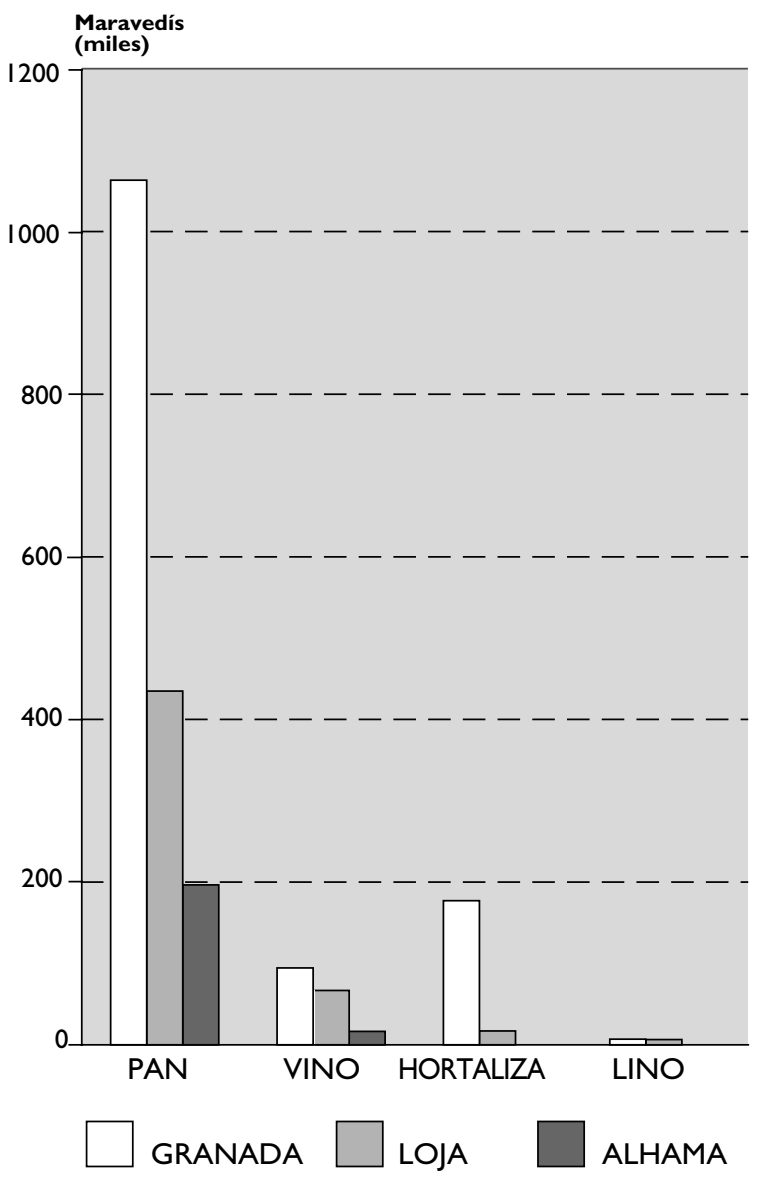

Gráfico 3. Producción agrícola de las ciudades: diezmos de 1506 


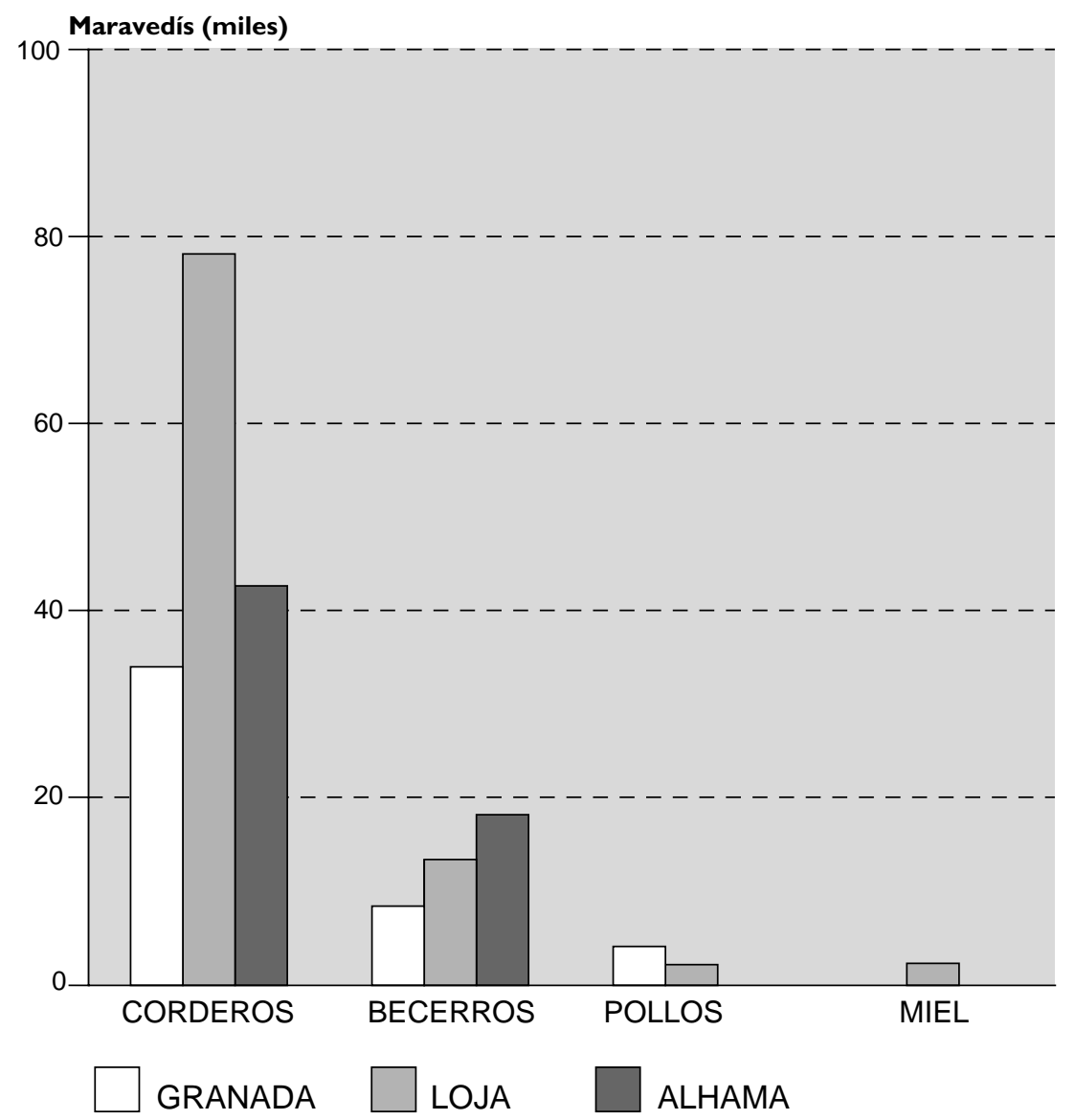

Gráfico 4. Producción ganadera de las ciudades: Diezmos de 1506

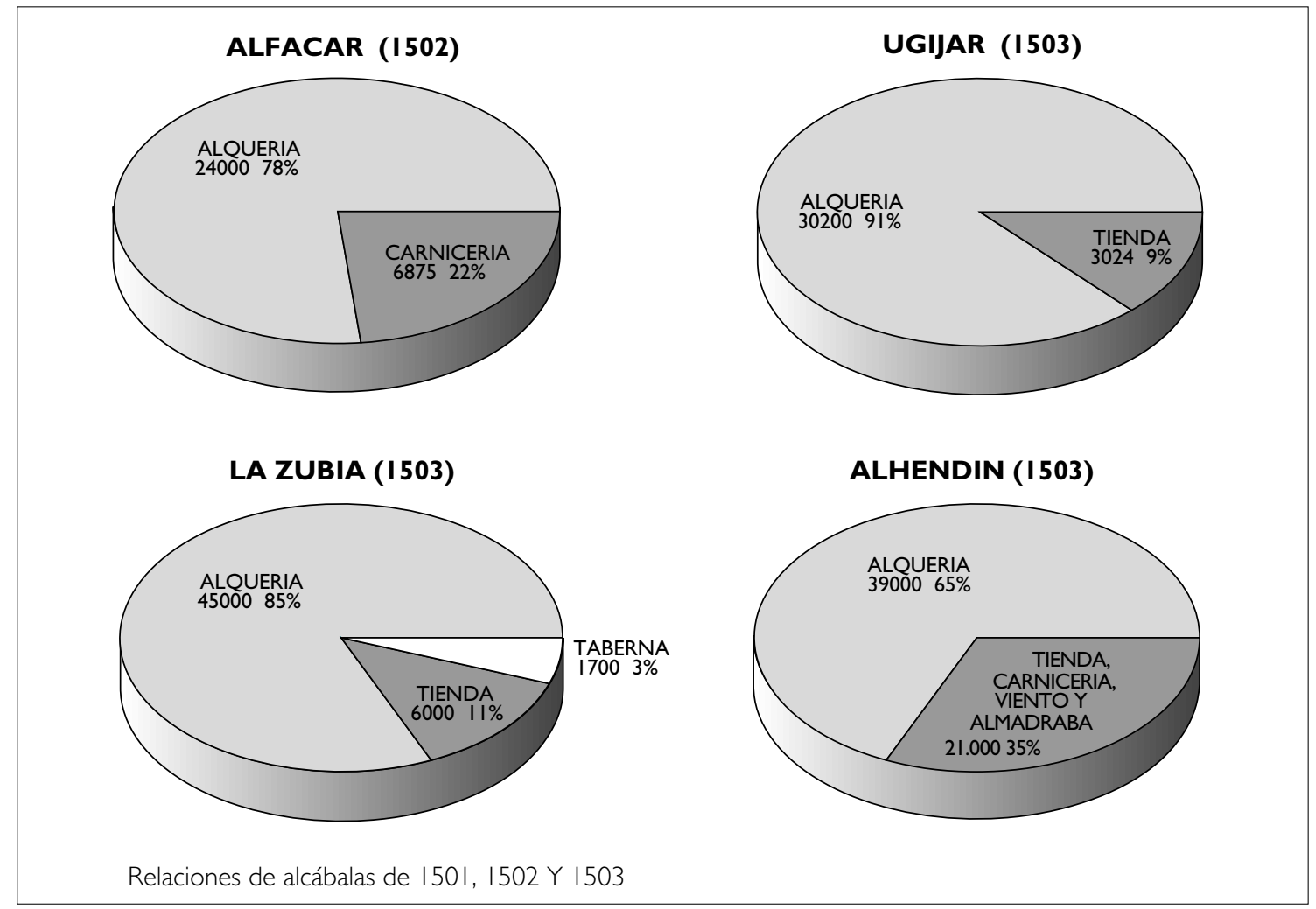

Gráfico 5. Alcabalas de las alquerías y sus negocios 


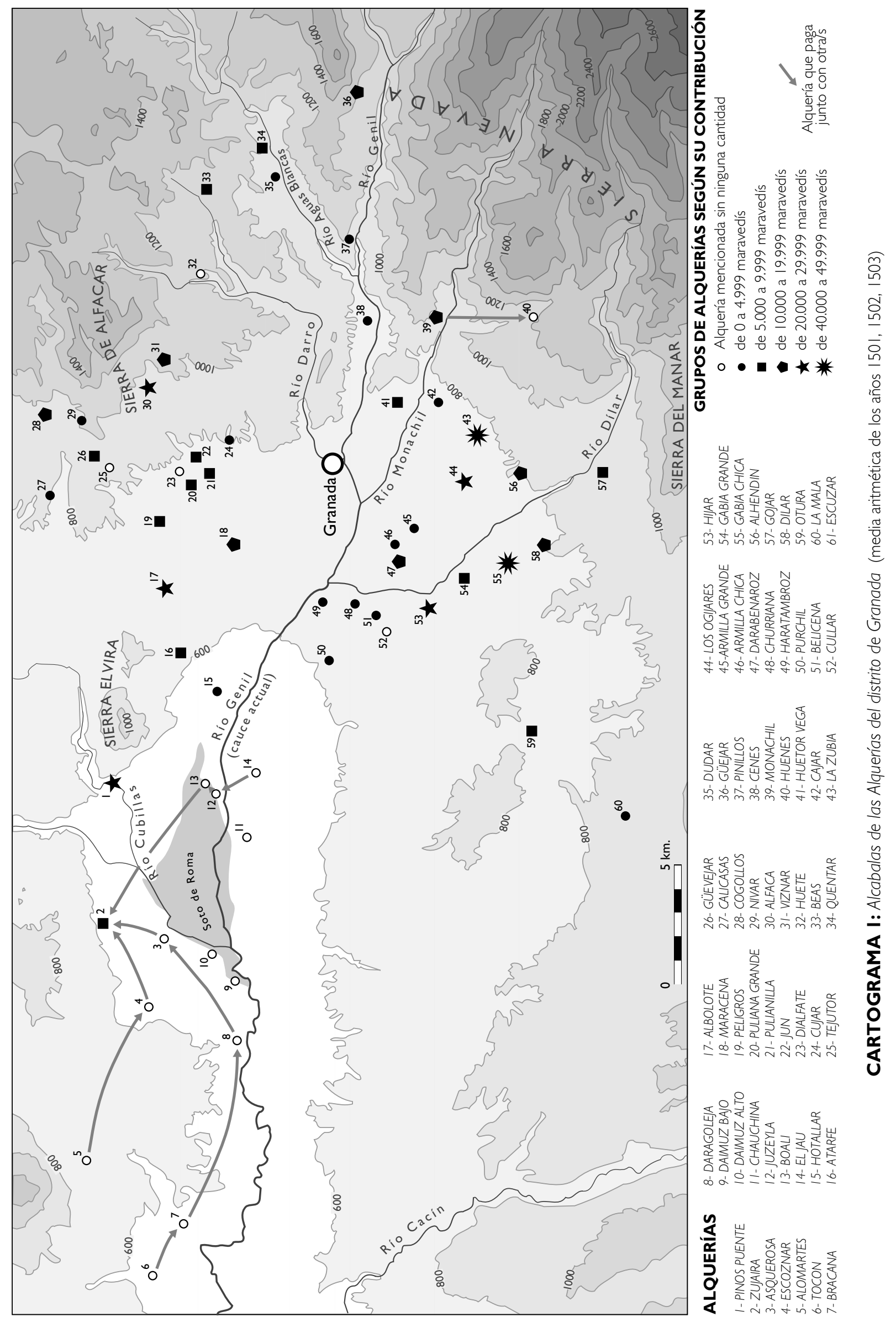




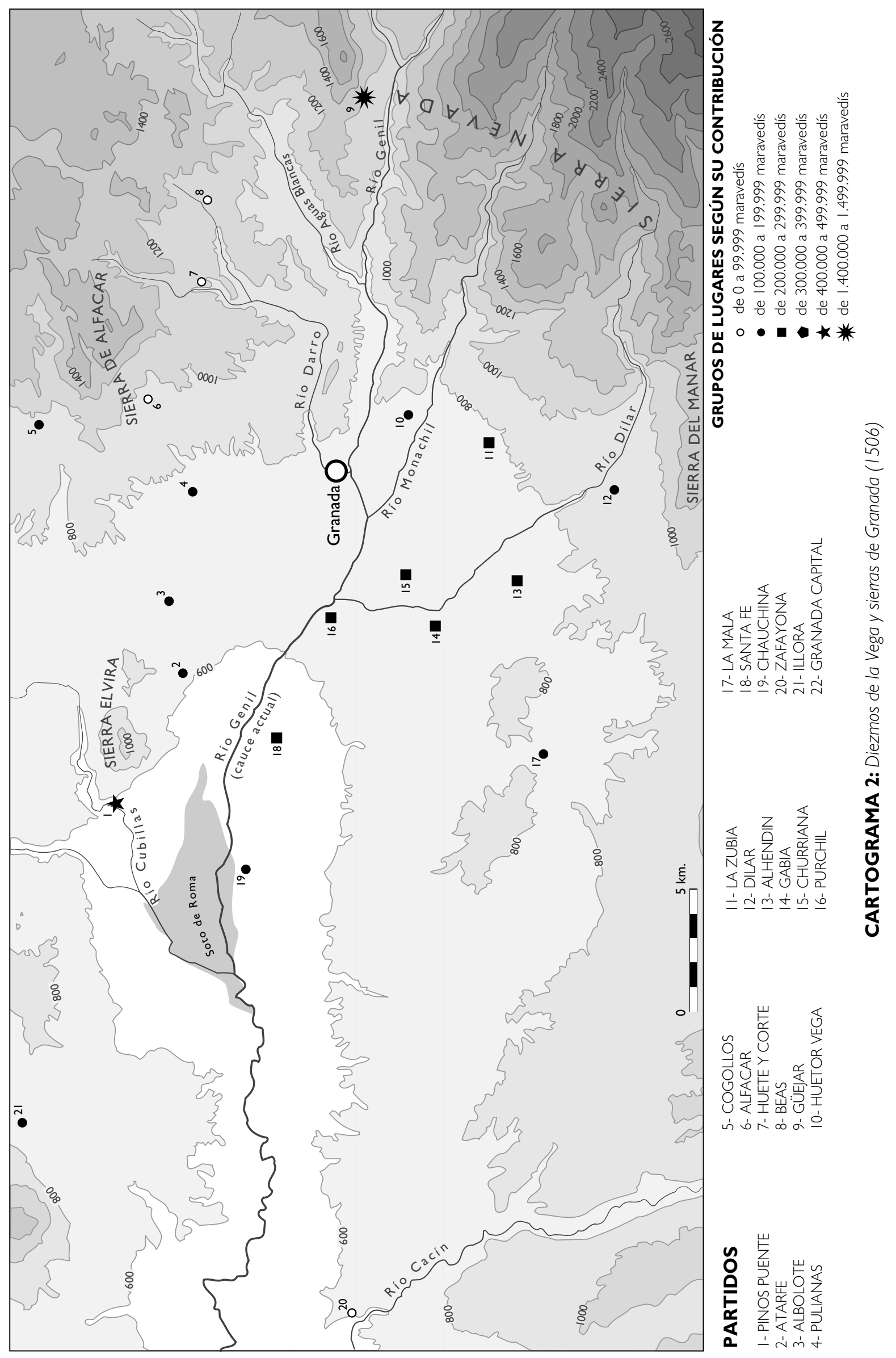




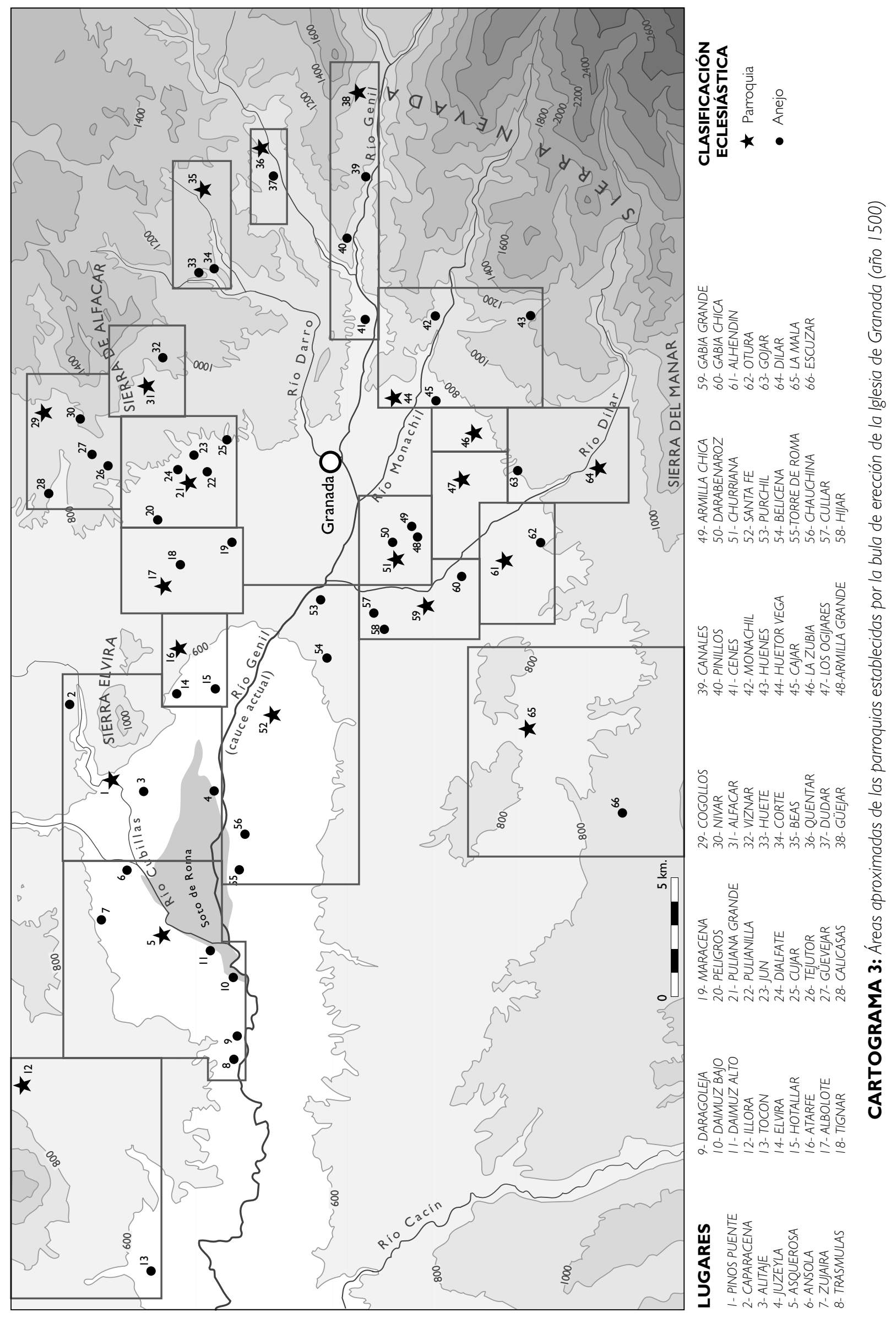

